\title{
Utilization of Anionic Polysaccharides to Improve the Stability of Rice Glutelin Emulsions: Impact of Polysaccharide Type, pH, Salt, and Temperature
}

Xingfeng $\mathrm{Xu}^{\mathrm{a}, \mathrm{b}}$, Liping Luo ${ }^{\mathrm{a}}$, Chengmei Liu ${ }^{\mathrm{a}, 1^{*}}$, David Julian McClements $^{\mathrm{b}, 1^{* *}}$ 
Keywords: rice glutelin; emulsion; stability; polysaccharide; environmental stress 


\section{Introduction}

There is considerable interest in replacing synthetic surfactants with natural emulsifiers in the food industry due to consumer demands for more label-friendly products (Huck-Iriart, Rincon-Cardona, \& Herrera, 2014; McClements \& Gumus, 2016; Ozturk, Argin, Ozilgen, \& McClements, 2015). Rice glutelin (RG) is hypoallergenic, has a high nutritive value, and contains many essential amino acids (Du, et al., 2013; Zhao, et al., 2012). However, the application of RG as an emulsifier is limited because of its relatively low water-solubility. In our previous studies, we showed that the solubility and emulsifying properties of RG can be enhanced by limited enzymatic hydrolysis to alter its surface hydrophobicity, charge characteristics, and molecular flexibility (Xu, et al., 2016a). In particular, it was demonstrated that stable emulsions could be formed using a hydrolyzed rice glutelin (HRG) with $2 \%$ degree of hydrolysis. These emulsions had good thermal stability, but they were highly sensitive to droplet aggregation when the $\mathrm{pH}$ or ionic strength was altered, which would limit the utilization of HRG as an emulsifier in many food products. The poor $\mathrm{pH}$ and salt stability of protein-coated oil droplets can be attributed to the fact that they are primarily stabilized by electrostatic repulsion (McClements, 2004).

The aggregation stability of protein-coated oil droplets can be enhanced by covering their surfaces with one or more layers of polysaccharide (Dickinson, 2011, 2013; McClements, 2010). Polysaccharides are usually used as functional food ingredients in emulsions due to their thickening and gelling properties (Niu, et al., 2015). However, they can also be used to improve the stability of protein-coated droplets by forming interfacial protein-polysaccharide complexes that reduce the van der Waals attraction and increase the steric and electrostatic repulsion between droplets (Dickinson, 2011; Guzey \& McClements, 2006b; Harnsilawat, Pongsawatmanit, \& McClements, 2006). Consequently, protein-polysaccharide-coated droplets are often more resistant to environmental stresses (e.g., $\mathrm{pH}$, ionic strength, heating, and freezing) than those coated by protein only (Dickinson, 2008; Guzey \& McClements, 2006a). The ability of polysaccharides to improve the stability of protein-coated oil droplets 
71 depends on the nature of the proteins and polysaccharides used, as well as the environmental conditions during and after interfacial complexation (Cheng, $\mathrm{Ma}, \mathrm{Li}$, 73 Yan, \& Cui, 2015; Niu, et al., 2016; Qiu, Zhao, \& McClements, 2015). In particular, 74 the formation of stable multilayer emulsions is highly dependent on the level of polysaccharide used (Guzey, et al., 2006a; Salminen \& Weiss, 2014). At too low polysaccharide concentrations, the emulsions become unstable due to bridging flocculation, i.e., the adsorption of a single polysaccharide molecule to the surfaces of two or more droplets. At intermediate polysaccharide concentrations, the droplet surfaces are completely covered by polysaccharide molecules and the droplets become stable to aggregation due to strong electrostatic and steric repulsion. At too high polysaccharide concentrations, the emulsions may become unstable due to depletion flocculation, i.e., the presence of non-adsorbed polysaccharide molecules in the aqueous phase generates a strong osmotic attraction between the droplets.

Previous studies have shown the stability of rice glutelin-coated oil droplets can be improved by covalently cross-linking the protein to an anionic polysaccharide (carrageenan) using the Maillard reaction (Du, et al., 2013). However, the utilization of chemically modified biopolymers is often unfavorable because they can no longer be considered as natural ingredients, which may lead to regulatory and labeling concerns. For this reason, there is interest in improving the stability of rice glutelin-coated droplets using non-covalent interactions with polysaccharides. However, there is currently little information about the nature of the interactions between rice glutelin and polysaccharides at oil-in-water interfaces, and their impact on emulsion properties.

In the present research, we therefore examined the ability of four anionic polysaccharides to improve the stability of rice glutelin emulsions based on an electrostatic deposition approach: Alginate, pectin, xanthan gum (XG), and gum arabic (GA). Alginate is a linear polysaccharide whose negative charge is due to the presence of carboxylic acid groups on the mannurronic and guluronic acid subunits (Paliandre,

98 Decker, \& McClements, 2007). Xanthan gum is a rigid linear polysaccharide with trisaccharide side-chains whose negative charge is due to carboxylic acid groups on the 100 guluronic acids in the side-chains (Dário, Hortêncio, Sierakowski, Neto, \& Petri, 2011). 
101 Pectin consists of a linear anionic backbone with regions of neutral side branches 102 attached at certain regions, whose charge is due to carboxylic acid groups on 103 galacturonic acids in the linear backbone (Courts, 2013). Gum arabic is a complex 104 mixture of polysaccharides and glycoproteins whose negative charge is mainly due to 105 carboxylic acid groups on guluronic acids in the polysaccharide fraction (Gulao, de 106 Souza, Andrade, \& Garcia-Rojas, 2016).

107 In this study, we characterized the major factors affecting the formation of stable 108 oil-in-water emulsion coated by HRG-polysaccharide layers. The stability of these 109 emulsions to environmental stresses ( $\mathrm{pH}$, ionic strength, and thermal treatment) was 110 analyzed to ascertain the type of foods they may be utilized within. This study provides 111 valuable information for optimizing the application of biopolymers as natural 112 stabilizers in the food industry.

\section{Materials and Methods}

\subsection{Materials}

Rice glutelin (93.42 wt\%, dry basis) was kindly provided by Golden Agriculture

116 Biotech Company Limited (Jiangxi, China). Corn oil was obtained from a commercial

117 food supplier (Mazola, ACH Food Companies, Memphis, TN). Xanthan gum with a 118 reported molecular weight of $6000 \mathrm{kDa}$ (Qiu, et al., 2015)) and gum arabic with a 119 reported molecular weight of $383 \mathrm{kDa}$ (Chang, Hu, \& McClements, 2016)) were 120 purchased from TIC Gums (Maryland, USA). Pectin with a reported molecular weight 121 of 73 kDa (Cuevas-Bernardino, Lobato-Calleros, Román-Guerrero, Alvarez-Ramirez, 122 \& Vernon-Carter, 2016)) and sodium alginate with a reported molecular weight of 350 123 kDa (Pamies, Schmidt, Martínez, \& de la Torre, 2010) were obtained from the Sigma 124 Chemical Co. (St. Louis, MO). Sodium chloride, sodium azide and all other chemicals 125 were of analytical grade and were also obtained from the Sigma Chemical Co. (St. 126 Louis, MO). Double-distilled water was used throughout to prepare all solutions and 127 emulsions. 


\subsection{HRG preparation}

129

130

131

132

133

134

135

136

HRG was prepared according to a method described previously (Xu, et al., 2016a). Briefly, $2 \mathrm{~g}$ of RG was added to double-distilled water $(30 \mathrm{~mL})$ with constant stirring for $1 \mathrm{~h}$ at $25^{\circ} \mathrm{C}$, and then adjusted to $\mathrm{pH} 8$ and $50{ }^{\circ} \mathrm{C}$. The $\mathrm{pH}$ of the suspension was kept constant throughout the entire period of hydrolysis by addition of $2.5 \mathrm{M} \mathrm{NaOH}$. After $4.2 \mathrm{~min}$ of hydrolysis by trypsin, the dispersion was heated to $95{ }^{\circ} \mathrm{C}$ for $10 \mathrm{~min}$ to inactivate the enzyme, followed by adjustment of the solution to $\mathrm{pH} 7.0 \mathrm{using} \mathrm{HCl}$ or $\mathrm{NaOH}$, and immediate cooling in water to room temperature. The mixture was centrifuged (TGL-20B, Anting Scientific Instrument Factory, Shanghai, China) at 4800 $\mathrm{g}$ for $10 \mathrm{~min}$ and the supernatant was freeze-dried. The degree of hydrolysis (DH) was calculated from the amount of base required to maintain a constant $\mathrm{pH}$ using the $\mathrm{pH}$-stat method (Adler-Nissen, 1986).

\subsection{Solution preparation}

Protein solution was prepared by dispersing $\mathrm{HRG}$ into $5 \mathrm{mM}$ phosphate buffer $(\mathrm{pH}$ 7), stirring for at least $3 \mathrm{~h}$ and then storing overnight at $4{ }^{\circ} \mathrm{C}$ to ensure complete hydration. Polysaccharide solutions (1 wt $\%)$ were prepared by dispersing corresponding weight amounts of powered materials into buffer solution ( $\mathrm{pH} 7.0)$, and stirring overnight at $4{ }^{\circ} \mathrm{C}$ to ensure complete hydration. The $\mathrm{pH}$ of all the solutions was readjusted to 7.0 if required.

\subsection{Emulsion preparation}

A primary oil-in-water emulsion was prepared by homogenizing $10 \mathrm{wt} \%$ corn oil with $90 \mathrm{wt} \%$ aqueous protein solution (5 wt\%, pH 7.0) using a high-shear mixer at 10,000 rpm for 2 min (M133/1281-0, Biospec Products, Inc., ESGC, Switzerland), followed by passing through a microfluidizer (M110Y, Microfluidics, Newton, MA) at 12,000 psi for 3 passes. A secondary emulsion ( $1 \mathrm{wt} \%$ corn oil, $0.3 \mathrm{wt} \% \mathrm{HRG}, 0-0.4 \mathrm{wt} \%$ polysaccharide, $\mathrm{pH} 7$ ) was formed by diluting the primary emulsion with different 
154

ratios of polysaccharide solution and buffer solution, then stirring for $30 \mathrm{~min}$. Finally, $0.005 \%(\mathrm{w} / \mathrm{w})$ of sodium azide was added as a microbial preservative.

\subsection{Particle size measurements}

The particle size distribution of the emulsions was analyzed by laser light scattering (Mastersizer 2000, Malvern Instruments, Worcestershire, UK). To avoid multiple scattering, samples were diluted with a buffer solution with the same $\mathrm{pH}$ and ionic composition as the sample being measured. Particle size data is represented as the surface-weighted mean diameter $\left(\mathrm{d}_{32}\right)$ calculated from the full particle size distribution.

\section{$2.6 \zeta$-potential measurements}

The $\zeta$-potential of the particles in the samples was determined by particle electrophoresis (Zetasizer Nano ZS-90, Malvern Instruments, Worcestershire, UK). To avoid multiple scattering effects, emulsions were diluted to 100-fold with buffer solutions of the same $\mathrm{pH}$ and ionic composition prior to measurement. The attenuation value was kept between 5 and 10. It should be noted that the $\zeta$-potential calculated by the particle electrophoresis instrument is based on the measured electrophoretic mobility and an appropriate theory (Smoluchowski). In highly aggregated systems, the assumptions underlying the theory may no longer be applicable, and therefore the results should be treated with caution.

\subsection{Confocal laser scanning microscopy (CLSM)}

Confocal imaging of emulsions was performed using an optical microscope (Leica TCS SP5, Leica Microsystems, Wetzlar, Germany) using a HCX PLAPO 60× objective at room temperature. $2 \mathrm{~mL}$ of emulsion was stained with $0.1 \mathrm{~mL}$ Nile Red solution (1 $\mathrm{mg} / \mathrm{mL}$ in ethanol) and $0.1 \mathrm{~mL}$ FITC $(10 \mathrm{mg} / \mathrm{mL}$ in dimethyl sulfoxide) to dye the oil and protein, respectively. An aliquot of sample was placed on a slide for visualization. Fluorescent dyes were excited using an Argon $488 \mathrm{~nm}$ laser and then the emitted light was collected at $515 \mathrm{~nm}$ for protein and $621 \mathrm{~nm}$ for oil, respectively. 
180

181

182

183

184

185

186

187

188

189

190

191

192

193

194

195

196

197

198

199

200

201

202

203

204

\subsection{Emulsion physical stability}

The stability of the emulsions was analyzed after they experienced a variety of different environmental stresses representative of those that might be experienced during manufacture, transport, or utilization.

\subsection{1 pH stability}

The initial primary and secondary emulsions $(\mathrm{pH} 7)$ were adjusted to $\mathrm{pH}$ values ranging from 7 to 2 by adding $\mathrm{HCl}$ or $\mathrm{NaOH}$ solutions while continuously stirring. After $1 \mathrm{~h}$ stirring, the $\mathrm{pH}$ was readjusted back to the required value if it had changed.

\subsubsection{Ionic strength stability}

The $\mathrm{pH}$ of the initial primary and secondary emulsions ( $\mathrm{pH} 7$ ) was adjusted to $\mathrm{pH}$ 3.5, and then different ratios of salt and buffer solution ( $\mathrm{pH} 3.5)$ were added to obtain a range of salt concentrations ( 0 to $500 \mathrm{mM} \mathrm{NaCl}$ ). The $\mathrm{pH}$ was measured and then adjusted back if necessary.

\subsubsection{Temperature stability}

The $\mathrm{pH}$ of the initial primary and secondary emulsions $(\mathrm{pH}$ 7) was adjusted to $\mathrm{pH}$ 3.5, and then the emulsions were placed in individual glass test tubes. The test tubes were then incubated in a water bath for $30 \mathrm{~min}$ at a fixed temperature $\left(30\right.$ to $\left.90{ }^{\circ} \mathrm{C}\right)$, and then they were cooled to room temperature by placing them in an ice water.

After exposure to these environmental stresses, samples were maintained at room temperature for $24 \mathrm{~h}$ before their particle size, $\zeta$-potential, and microstructure were measured. The visual appearance of samples stored for $48 \mathrm{~h}$ was also recorded.

\subsection{Statistical analyses}

All analysis was carried out in triplicate and repeated twice per sample. The mean and standard deviations were calculated from these values using statistical analysis software (SPASS 19.0, SPSS Inc., Chicago, IL). 


\section{Results and discussion}

\subsection{Influence of polysaccharide addition on emulsion characteristics}

The purpose of these experiments was to examine the influence of polysaccharide

208 addition on the stability of oil-in-water emulsions containing HRG-coated lipid 209 droplets. Secondary emulsions (1 wt\% corn oil, 0.3 wt\% HRG, 0-0.4 wt\% 210 polysaccharide, $\mathrm{pH}$ 7) were formed by diluting primary emulsions with different ratios 211 of polysaccharide solution and buffer solution, and then adjusting the emulsions to $\mathrm{pH}$ 212 3.5. The mean particle diameter $\left(\mathrm{d}_{32}\right)$, electrical characteristics ( $\zeta$-potential) and 213 appearance of the emulsions at $\mathrm{pH} 3.5$ and 7 were compared.

\section{$214 \quad$ 3.1.1 Stability characteristics}

$215 \quad p H$ 3.5: At this $\mathrm{pH}$, the mean particle diameter of the primary emulsion was 216 relatively large $\left(d_{32}=13.9 \mu \mathrm{m}\right)$ in the absence of polysaccharides and the emulsions 217 were unstable to creaming (Fig. 1), which can be attributed to aggregation of the 218 HRG-coated droplets near their isoelectric point $(\mathrm{pH} \approx 4)$. In this $\mathrm{pH}$ range, the 219 electrostatic repulsion between the droplets is not large enough to overcome attractive 220 interactions such as van der Waals and hydrophobic attraction. An increase in mean 221 particle diameter was observed when relatively low concentrations $(0.01 \mathrm{wt} \%)$ of 222 polysaccharide were added (Fig. 1a) and the emulsions were still highly unstable to 223 creaming (Fig. 1c). These results suggest that addition of this low level of 224 polysaccharide actually promoted further droplet aggregation, which can be attributed 225 to charge neutralization and bridging flocculation (Guzey, et al., 2006a). The positive 226 charge on the droplets was reduced by the adsorption of the anionic polysaccharide 227 molecules (Section 3.2), thereby reducing the electrostatic repulsion between the 228 droplets. Furthermore, when the amount of polysaccharide present is insufficient to 229 fully coat the droplet surfaces, then one polysaccharide molecule adsorbs to the 230 surfaces of several droplets resulting in bridging flocculation (Joye, Nelis, \& 231 McClements, 2015). At higher polysaccharide concentrations, the aggregation 
stability of the emulsions depended on the type of polysaccharide used (Fig. 1).

For alginate and gum arabic, the mean particle diameter decreased when the polysaccharide concentration exceeded $0.05 \%$, but the final values were fairly similar to those of the initial polysaccharide-free emulsions (Fig. 1a). In addition, the emulsions were still highly unstable to creaming (Fig. 1c), which can be attributed to their relatively large particle size. These results suggest that the polysaccharide molecules wrapped around flocs containing numerous protein-coated oil droplets, rather than around individual protein-coated droplets. Interestingly, it has previously been reported that the addition of alginate to WPI-stabilized oil-in-water emulsions actually improved their aggregation stability at $\mathrm{pH} 5$ (Fioramonti, Martinez, Pilosof, Rubiolo, \& Santiago, 2015a). These differences in the addition of polysaccharides on emulsion stability may be attributed to a number of phenomena. First, whey protein and rice glutelin have different molecular characteristics, such as molecular weight, conformation, flexibility, and electrical charge distribution (Huck-Iriart, et al., 2014; $\mathrm{Xu}$, et al., 2016b), which would be expected to affect the interfacial properties of the protein-coated droplets in the emulsions. Second, the molecular characteristics of alginates used in different studies are likely to be different, which may have influenced the nature of the polysaccharide coating formed.

For xanthan gum and pectin, the mean particle diameter was much lower at 0.1 and $0.2 \mathrm{wt} \%$ polysaccharide than at lower levels (Fig. 1a) and the emulsions became stable to creaming (Fig. 1c), which suggested that the polysaccharides wrapped around individual protein-coated droplets, rather than promoting bridging flocculation. At higher polysaccharide concentrations $(0.4 \%)$, the particles in the emulsions containing xanthan gum remained relatively small, but those in the emulsions containing pectin increased appreciably (Fig. 1a). This suggests that the pectin molecules promoted depletion flocculation when they were present in the aqueous phase above a critical level, whereas the xanthan molecules did not (Aoki, Decker, \& McClements, 2005; Guzey, et al., 2006a). 
as molecular weight, conformation, branching, and charge density (Guzey, et al.,

263 2006a). Differences in these molecular characteristics impact the affinity of the

264 polysaccharide molecules for the protein-coated oil droplet surfaces, as well as the rate

265 of polysaccharide adsorption (Chang, et al., 2016). In addition, they alter the strength

266 and range of the colloidal interactions between the droplets, such as electrostatic, steric,

267 and van der Waals.

$268 \quad p H 7$ : At this $\mathrm{pH}$, the mean particle diameter of the protein-coated oil droplets in 269 the primary emulsions was relatively small $(0.18 \mu \mathrm{m})$, which can be attributed to the 270 relatively strong electrostatic repulsion between the highly charged droplets. There 271 was a slight increase in the mean particle diameter of the secondary emulsions with 272 increasing polysaccharide concentration for all systems (Fig. 1b). In addition, 273 creaming instability was observed in the emulsions containing alginate and pectin at 274 higher polysaccharide levels, but not in the emulsions containing gum arabic and 275 xanthan gum (Fig.1c). These results suggest that droplet aggregation had occurred in 276 the emulsions. The addition of non-adsorbed polysaccharides to emulsions is known to increase the attractive osmotic forces between the oil droplets due to a depletion 278 mechanism (McClements, 2015). As a result, the droplets may become flocculated 279 above a critical polysaccharide concentration, which can then promote coalescence 280 because the droplets are forced together. The critical polysaccharide concentration 281 (wt\%) required to promote depletion flocculation in an emulsion depends on the 282 number and size of the polymer molecules (Dickinson, 2010). Typically, this critical 283 concentration decreases as the number density and effective size of the polysaccharide 284 molecules in solution increases. The gum arabic molecules may not have promoted 285 creaming because they have relatively small molecular dimensions (low radius of 286 hydration) due to the fact that they are highly branched, and therefore they were not 287 present at a sufficiently high concentration to cause depletion flocculation. 288 Conversely, the xanthan gum molecules may not have promoted creaming for a number 289 of reasons. First, xanthan gum molecules have a relatively high charge density, rigidity, 290 and molecular weight and so they may have adsorbed to positive patches on the 291 surfaces of the protein-coated droplets, which would increase the electrostatic and 
steric repulsion between them (Protonotariou, Evageliou, Yanniotis, \& Mandala, 2013; Qiu, et al., 2015). Second, xanthan gum is highly effective at increasing the viscosity of aqueous solutions, which may have prevented the oil droplets from creaming, even if they were flocculated (Chen, et al., 2016).

\subsubsection{Electrical characteristics}

pH 3.5: At this $\mathrm{pH}$, the $\zeta$-potential of the HRG-coated droplets was $+18 \mathrm{mV}$ in the absence of polysaccharides (Fig. 2a). This positive charged can be attributed to the fact that the adsorbed proteins were below their isoelectric point $(\mathrm{pI} \approx 4)$ at $\mathrm{pH} 3.5$. The $\zeta$-potential went from positive to negative when the polysaccharide level was increased, which suggested that anionic polysaccharide molecules adsorbed to the surfaces of cationic HRG-coated droplets. The negative charge reached a relatively constant value when the polysaccharide level exceeded about $0.1 \mathrm{wt} \%$, suggesting that the droplet surfaces had become saturated with polysaccharide, which is in agreement with previous studies ( $\mathrm{Li} \& \mathrm{McClements,} 2013$ ). The final values of the droplet charge depended on polysaccharide type: $-40 \mathrm{mV}$ for alginate; $-37 \mathrm{mV}$ for xanthan gum; -22 $\mathrm{mV}$ for gum arabic; and, $-18 \mathrm{mV}$ for pectin. These values will depend on the electrical characteristics of the polysaccharides used, as well as their packing and orientation at the droplet surfaces. Interestingly, there appeared to be little correlation between the electrical properties of the polysaccharide-coated droplets (Fig. 2a), and the aggregation stability of the emulsions (Fig. 1a). Alginate and xanthan gum led to the highest negative charge on the droplets, but alginate led to unstable emulsions, whereas xanthan gum led to stable ones. Moreover, pectin and gum arabic led to the lowest negative $\zeta$-potentials on the droplets, but pectin led to stable emulsions at intermediate concentrations, whereas gum arabic led to unstable ones at all concentrations. As reported previously, the stability of emulsions containing protein-polysaccharide coated droplets is not only influenced by the electrical characteristics of the adsorbed layer, but also by the thickness and porosity of the polysaccharide layer (Chang, et al., 2016; Gu, Decker, \& McClements, 2005). A possible reason for the poor stability of the emulsions containing alginate and gum arabic is that they formed relatively thin 
layers, and so the steric repulsion between the droplets was less than that for the other polysaccharides (Razzak, Kim, \& Chung, 2016).

pH 7: In the absence of polysaccharides, the $\zeta$-potential of the HRG-coated 324 droplets was strongly negative (around $-40 \mathrm{mV}$ ), which can be attributed to the fact that $325 \mathrm{pH} 7$ was well above the isoelectric point of the proteins. The $\zeta$-potential remained 326 highly negative for all polysaccharide types and concentrations added to the emulsions, 327 although there were some differences (Fig. 2b). At this $\mathrm{pH}$, both the polysaccharides 328 and protein-coated droplets are negatively charged, and therefore one might expect a 329 limited interaction between them because of electrostatic repulsion (Fioramonti, 330 Martinez, Pilosof, Rubiolo, \& Santiago, 2015b). The observed changes in the measured $331 \zeta$-potential may have arisen from two main effects: (i) the adsorption of polysaccharides 332 to the droplet surfaces: (ii) the contribution of non-adsorbed polysaccharides to the 333 electrophoretic signal used to calculate the droplet potential(Fioramonti, et al., 2015b).

\subsection{Influence $\mathrm{pH}$ on emulsion properties}

\subsubsection{Electrical characteristics}

Emulsions used in food products are exposed to a range of different $\mathrm{pH}$ values, and so it is practically important to investigate the influence of $\mathrm{pH}$ on emulsion stability. The $\zeta$-potential of the protein-coated droplets in the primary emulsions went from negative $(-39 \mathrm{mV})$ to positive $(+26 \mathrm{mV})$ when the $\mathrm{pH}$ was reduced from 7 to 2 , with a value of zero charge around $\mathrm{pH} 4$ (Fig. 3a). This effect can be attributed to changes in the electrical properties of the adsorbed proteins when solution $\mathrm{pH}$ is altered from above to below their isoelectric point. In general, the $\zeta$-potential of the secondary emulsions was more negative (or less positive) than that of the primary emulsions at relatively low $\mathrm{pH}$ values, which suggested that anionic polysaccharides adsorbed to the protein-coated droplet surfaces in this $\mathrm{pH}$ range (Qiu, et al., 2015). The nature of the protein-polysaccharide interaction depends on both the number and distribution of the charges on the two biopolymer molecules at a specific $\mathrm{pH}$ (Gu, et al., 2005). Anionic polysaccharide molecules adsorb onto protein-coated oil droplets around and below the 
isoelectric point of the protein molecules due to the presence of cationic regions on the protein surfaces (Dickinson, 2011). Conversely, little or no adsorption occurs at neutral

$351 \mathrm{pH}$ because the strong negative charge on the protein-coated oil droplet surfaces repels 352 the anionic polysaccharide molecules (Fioramonti, et al., 2015b; Qiu, et al., 2015). In 353 our research, the alginate-/XG-HRG complexes were formed when $\mathrm{pH}$ was lower than 354 6, while the pectin-/GA-HRG complexes could be found when $\mathrm{pH}$ was lower than 5 . 355 These results are consistent with the fact that the alginate and XG have a higher charge 356 density than the pectin and GA, as demonstrated by the higher surface charge of the droplets at saturation (Fig. 2a) and by the charge characteristics of the molecules in 358 solution (Fig. 3b).

The $\mathrm{pH}$ dependence of the $\zeta$-potential of the polysaccharide molecules in aqueous 360 solutions was measured to obtain additional information about their electrical 361 characteristics (Fig. 3b). In general, the negative charge on the polysaccharide 362 molecules increased with increasing $\mathrm{pH}$, but there were distinct differences in the 363 magnitude of the $\zeta$-potentials. For example, at neutral $\mathrm{pH}$, the magnitude of the 364 negative charge decreased in the following order: $X G>$ alginate $>$ pectin $>$ GA (Fig. $3 b$ ), 365 which is indicative of differences in the charge densities of the polysaccharide 366 molecules. The relatively low magnitude of the $\zeta$-potential of the polysaccharides 367 observed under the most acidic conditions can be attributed to the fact that this $\mathrm{pH}$ is 368 well below the $\mathrm{pK}_{\mathrm{a}}$ value of their carboxyl groups (Bokkhim, Bansal, Grondahl, \& 369 Bhandari, 2015; Joye, et al., 2015; Lim \& Roos, 2015; Moreau, Kim, Decker, \& 370 McClements, 2003; Xiang, Liu, Fan, \& Gao, 2015). The dependence of the $\zeta$-potential 371 on $\mathrm{pH}$ was governed by the nature of the polysaccharides used (Fig. 3a). Interestingly, 372 the $\zeta$-potential values of the secondary emulsions containing pectin were fairly similar 373 to those containing GA, even though the charge densities of these two types of 374 polysaccharide molecules in solution were appreciably different (Fig. 3b). Similarly, 375 the $\zeta$-potentials of the secondary emulsions containing alginate and $\mathrm{XG}$ were fairly 376 similar, even though the charge densities of the two polysaccharides in solution were 377 quite different (Figs. 3a and 3b). These results may be due to differences in the 378 location and orientation of the charged groups on the polysaccharide molecules after 
they adsorb to the droplet surfaces (Fig.3b). Furthermore, for gum arabic, the

$380 \zeta$-potential of the primary and secondary emulsions only deviated below $\mathrm{pH} 5$, 381 suggesting that the polysaccharide molecules did not adsorb to the droplet surfaces until 382 relatively low $\mathrm{pH}$ values were reached. For pectin, the $\zeta$-potentials deviated below $\mathrm{pH} 6$, 383 suggesting that this polysaccharide adsorbed to the droplet surfaces at a slightly higher $384 \mathrm{pH}$ than gum arabic. For xanthan gum and alginate, the difference in $\zeta$-potentials of 385 the primary and secondary emulsions was already pronounced at $\mathrm{pH} 6$, which 386 suggested that these polysaccharides adsorbed at a considerably higher $\mathrm{pH}$ than the 387 other two types. This effect can be attributed to the higher charge density of xanthan 388 gum and alginate compared to pectin and gum arabic. Our results are consistent with 389 those of an earlier study (Qiu, et al., 2015) that reported that xanthan gum interacted 390 with cationic patches on protein-coated droplets at relatively high $\mathrm{pH}$ values.

391 The $\zeta$-potential values were around zero for all the secondary emulsions at $\mathrm{pH} 2$, 392 which would be expected to lead to a low electrostatic repulsion between the droplets. 393 However, the secondary emulsions containing pectin were fairly stable to droplet 394 aggregation and creaming at this low pH value (Fig. $3 \mathrm{c}$ and $3 \mathrm{~d}$ ). Previous researchers 395 have reported that this may be due to steric repulsion by polysaccharides that have long 396 neutral side chains, such as pectin (Azarikia \& Abbasi, 2016; Ray \& Rousseau, 2013; 397 Wang, Chen, \& Lü, 2014). In general, the stability of biopolymer-coated droplets to 398 aggregation depends on numerous factors. For the rice-glutelin emulsions, 399 electrostatic repulsion was the only long-range repulsive force operating between the 400 droplets (in addition to short-range steric repulsion due to the thin protein layer). Thus, 401 the larger the magnitude of the $\zeta$-potential in the primary emulsions, the stronger the 402 repulsive forces, and the less droplet aggregation would be expected. For the rice 403 glutelin-polysaccharide emulsions, the range of the steric repulsion would be much 404 longer due to the thick polysaccharide layer present, thereby improving their 405 aggregation stability by generating both electrostatic and steric repulsion. Thus, the 406 overall emulsion stability is not only influenced by the electrical characteristics of the 407 interfacial layer, but also by other factors that affect the thickness and porosity of the 408 polysaccharide layer. 


\subsubsection{Stability characteristics}

The $\mathrm{pH}$ dependence of the mean particle diameter and creaming stability of the primary and secondary emulsions was also measured (Figs. 3c and 3d). In the absence of polysaccharide, the primary emulsions were stable at $\mathrm{pH} 6$ and 7, but became highly unstable to aggregation and creaming when the $\mathrm{pH}$ was at 5 or below, which can be attributed to the reduction in droplet charge around the isoelectric point (Fig. 3a). In the presence of the polysaccharides, the stability of the emulsions was highly dependent on polysaccharide type.

Interestingly, the secondary emulsions containing pectin remained relatively stable to droplet aggregation (Fig. 3c) and creaming (Fig. 3d) across the entire pH range. These results suggest that pectin is a highly effective polysaccharide for improving the stability of protein-coated oil droplets, which has also been reported in other recent studies (Qiu, et al., 2015; Zhao, Wei, Wei, Yuan, \& Gao, 2015). Presumably, the pectin molecules adsorbed to the protein-coated droplet surfaces before the droplets could aggregate with each other, and then formed a thick charged interfacial layer that increased the electrostatic and steric repulsion between the droplets.

The secondary emulsions containing xanthan gum were relatively stable to droplet aggregation and creaming from $\mathrm{pH} 7$ to 4, but unstable at lower $\mathrm{pH}$ values (Figs. 3c and $3 \mathrm{~d}$ ). The reason that the xanthan gum-covered droplets aggregated at low $\mathrm{pH}$, whereas the pectin-covered ones did not, can be attributed to differences in the steric repulsion generated by the interfacial layers. Xanthan gum has relatively short anionic side chains, whereas pectin has relatively long neutral side chains, which may protrude into the surrounding aqueous phase and generate a strong long-range steric repulsion (Wang, et al., 2014). Interestingly, the emulsions containing alginate were unstable to aggregation and creaming over a wider $\mathrm{pH}$ range ( $\mathrm{pH} 2$ to 5) than the ones containing xanthan gum, even though the $\zeta$-potential versus $\mathrm{pH}$ profile of the two systems was very similar (Fig. 3a). One possible reason for this phenomenon is that alginate is a linear polysaccharide without side chains (Razzak, et al., 2016). As a result, it may lay flat against the droplet surfaces and therefore not be as effective as 
xanthan or pectin at generating a steric repulsion (Gulao, et al., 2016).

The secondary emulsions containing gum arabic were stable to droplet aggregation and creaming at $\mathrm{pH} 7$ and 6, but highly unstable from $\mathrm{pH} 5$ to 2 (Fig. 3c). Consequently, their $\mathrm{pH}$ stability was very similar to that of the primary emulsions. The most likely reason for this similarity is that the gum arabic molecules only had a relatively low charge density, and therefore they did not adsorb to the surfaces of the protein-coated droplets before they aggregated with each other. Indeed, this hypothesis is supported by the $\zeta$-potential measurements, which indicate that the gum arabic only adsorbed strongly to the droplet surfaces at $\mathrm{pH} 4$ and below (Fig. 3a), which is less than the $\mathrm{pH}$ value where the droplets in the primary emulsion had strongly aggregated (Fig. 3c).

These results show that the emulsions containing pectin or xanthan gum were the most stable, and so only these systems were examined in the subsequent experiments.

\subsubsection{Microstructure}

Confocal fluorescence microscopy was used to obtain information about the impact of $\mathrm{pH}$ on the microstructure of selected emulsions (Fig. 3e). At $\mathrm{pH} 7$, the microscopy images indicated that the primary emulsions contained small uniformly distributed oil droplets, indicating that these systems were stable to aggregation due to the strong electrostatic repulsion between the droplets. Secondary emulsions containing xanthan gum or pectin were also stable at $\mathrm{pH} 7$, which can again be attributed to the strong electrostatic repulsion between the droplets, and the fact that the level of polysaccharide used was not high enough to induce depletion flocculation. In contrast, at $\mathrm{pH} 3.5$, the droplets in the primary emulsions were highly aggregated due to the reduced electrostatic repulsion between them. However, extensive droplet aggregation was inhibited in the secondary emulsions containing xanthan gum or pectin at $\mathrm{pH}$ 3.5. This behavior can be attributed to the stronger electrostatic and steric repulsion between polysaccharide coated droplets (Qiu, et al., 2015; Zhao, et al., 2015). The microscopy results therefore strongly supported the light scattering measurements and visible observations discussed earlier. 
Emulsions may be used in food and beverage products with different salt levels, and therefore it is important to establish the impact of ionic strength on droplet stability.

471 The influence of $\mathrm{NaCl}$ level on the mean particle diameter and $\zeta$-potential of emulsions 472 containing $0.1 \%$ xanthan gum or pectin at $\mathrm{pH} 3.5$ was therefore measured (Figs. $4 \mathrm{a}$ and $4734 \mathrm{~b})$. In the absence of the polysaccharide covering the droplets were highly unstable to 474 aggregation (data not shown). The secondary emulsion containing pectin was stable to droplet aggregation and creaming from 0 to $100 \mathrm{mM} \mathrm{NaCl}$ (Fig. 4a). This result suggests that the combination of the repulsive interactions (electrostatic and steric repulsion) acting between the pectin-covered droplets was strong enough to overcome the combination of attractive interactions (van der Waals, depletion, and hydrophobic) (Shi, et al., 2015). However, as higher $\mathrm{NaCl}$ levels, the droplets became unstable to aggregation and creaming. This effect was attributed to the decrease in electrostatic repulsion between the oil droplets upon the addition of $\mathrm{NaCl}$, i.e., electrostatic screening (Niu, et al., 2015). In addition, the presence of high levels of salt may have weakened the attractive electrostatic interactions between the protein and polysaccharide molecules at the droplet surfaces, which could have caused some of the polysaccharide molecules to become attached to more than one droplet and promote bridging flocculation.

Compared with pectin, the oil droplets covered with xanthan gum had relatively high stability to salt addition across the whole range studied, with little evidence of droplet aggregation or creaming (Fig. 4a). Interestingly, there was actually an initial 490 decrease in mean particle diameter in the emulsions containing xanthan gum with 491 increasing salt content: from around $1.01 \mu \mathrm{m}$ to $0.81 \mu \mathrm{m}$ when the $\mathrm{NaCl}$ level was 492 increased from 0 to $100 \mathrm{mM}$. There are a number of possible reasons for this decrease 493 associated with a reduction in the strength of electrostatic interactions in the presence of 494 salt. First, salt addition will have weakened intra-molecular electrostatic repulsion 495 between negatively charged groups on the xanthan molecules, thereby causing the 496 effective size of the molecules to decrease because the chains could pack closer 
together (Protonotariou, et al., 2013; Rochefort \& Middleman, 1987). This effect may

498 have reduced the thickness of the adsorbed xanthan gum coating. Second, salt 499 addition will have weakened electrostatic attraction between the negative groups on the 500 xanthan molecule and positive groups on the protein-coated droplets (Protonotariou, et 501 al., 2013). This may have enabled some rearrangement of the xanthan gum molecules 502 at the droplet surfaces leading to a more compact and thinner polysaccharide coating 503 (Protonotariou, et al., 2013). Alternatively, it may have caused some of the xanthan 504 gum molecules to be desorbed from the droplet surfaces, again leading to a thinner 505 polysaccharide coating.

506 The HRG-xanthan gum and HRG-pectin coated droplets were negatively charged 507 at all $\mathrm{NaCl}$ levels used, but the magnitude of the $\zeta$-potential decreased as the $\mathrm{NaCl}$ level 508 increased: from -17 to $-2 \mathrm{mV}$ for pectin and from -33 to $-15 \mathrm{mV}$ for xanthan gum (Fig. 509 4b). This effect may be the result of a number of phenomena, including electrostatic 510 screening, ion binding, polysaccharide rearrangement, and polysaccharide desorption 511 (Guzey, et al., 2006a; Li, Li, Shen, Niu, \& Fu, 2016).

512 Additional information about the impact of ionic strength on the stability of the 513 secondary emulsions was obtained using confocal fluorescence microscopy (Fig. 4c). 514 At low $\mathrm{NaCl}$ levels, there was no significant change in the microstructure of the 515 emulsions containing pectin or XG compared to that containing no salt, indicating that 516 the repulsive interactions between the droplets were still strong enough to overcome the 517 attractive interactions (Shi, et al., 2015). However, large aggregates were observed in 518 the secondary emulsions containing pectin at higher salt levels $(500 \mathrm{mM} \mathrm{NaCl})$, which 519 suggested that some droplet flocculation or coalescence had occurred. As discussed 520 earlier, this may have been due to electrostatic screening, ion binding, interfacial 521 rearrangements, and/or polysaccharide desorption (Guzey, et al., 2006a; Li, et al., 2016). 522 In contrast, the secondary emulsions containing xanthan gum were fairly stable to 523 aggregation even at high salt concentration. The microscopy results are therefore in 524 good agreement with the light scattering measurements and visual observations of the 525 samples discussed earlier. 
In many commercial applications it is important that an emulsion is able to 528 withstand thermal treatments during its production, storage, or utilization. We therefore 529 examined the impact of heat treatments $\left(30-90{ }^{\circ} \mathrm{C}\right)$ on the stability of secondary 530 emulsions containing either xanthan gum or pectin $(\mathrm{pH} 3.5,0 \mathrm{mM} \mathrm{NaCl})$. Both types of 531 secondary emulsion appeared visibly stable to creaming after the heat treatments (Fig. 532 5a), however there were changes in particle size in some of the emulsions (Fig. 5b). The 533 mean particle diameter $\left(\mathrm{d}_{32}\right)$ of the HRG emulsions coated with pectin and xanthan gum 534 at $90{ }^{\circ} \mathrm{C}$ were 2.1 and 1.2 times larger than that of the control (emulsions treated at $53530^{\circ} \mathrm{C}$ ), respectively. The mean particle diameter of the emulsions containing pectin 536 remained fairly constant from 30 to $60{ }^{\circ} \mathrm{C}\left(d_{32}=0.33\right.$ to $\left.0.37 \mu \mathrm{m}\right)$, but increased 537 somewhat from 70 to $90{ }^{\circ} \mathrm{C}\left(d_{32}=0.43\right.$ to $\left.0.70 \mu \mathrm{m}\right)$. On the other hand, the mean 538 particle diameter of the emulsions containing xanthan gum remained relatively stable 539 across the entire temperature range studied ( $d_{32}=1.08$ to $\left.1.29 \mu \mathrm{m}\right)$, and there was little 540 change in their microstructure (Fig. 5c). The confocal fluorescence microscopy images 541 also showed that there was a slight increase in droplet size in the emulsions containing 542 pectin (Fig. 4c), but that the droplets still remained evenly dispersed, which may 543 account for the fact that no visible creaming occurred. Overall, these results suggest 544 that the emulsions containing xanthan gum were more stable to heating than those 545 containing pectin. This may have been due to a stronger electrostatic and steric 546 repulsion between the droplets coated by xanthan gum.

547 There was no significant change in the $\zeta$-potential of the secondary emulsions $(-35$ $548 \mathrm{mV}$ for xanthan gum and $-18 \mathrm{mV}$ for pectin, respectively) upon thermal treatment (Fig. 5495 b), suggesting that heating did not strongly influence the overall composition or 550 structure of the polysaccharide coatings (Güzey \& McClements, 2006).

\section{Conclusions}

552 This study compared the effectiveness of four different anionic polysaccharides at 
553 improving the physical stability of emulsions containing oil droplets coated by

554 hydrolyzed rice glutelin. Pectin and xanthan gum were much more effective at 555 stabilizing the emulsions than gum arabic or alginate, which was attributed to 556 differences in molecular properties such as charge density, branching, rigidity, and 557 dimensions. The best pH-stability of the emulsions was obtained by covering the 558 HRG-coated droplets with pectin, whereas the best salt- and thermal-stability was 559 obtained by covering them with xanthan gum. In future studies, it would be useful to 560 use more detailed analytical tools to provide information about differences in interfacial 561 properties, such as electron microscopy or interfacial rheology. This study provides 562 valuable information that may increase the utilization of rice proteins as emulsifiers in 563 the food industry.

\section{Acknowledgements}

565 This study was supported by the Freedom Explore Program of State Key 566 Laboratory of Food Science and Technology of Nanchang University (No. 567 SKLF-ZZB-201512). This material was also partly based upon work supported by the 568 Cooperative State Research, Extension, Education Service, USDA, Massachusetts 569 Agricultural Experiment Station (MAS00491) and USDA, NRI Grants (2011-67021, 570 2013-03795, and 2014-67021).

\section{$571 \quad$ References}

Adler-Nissen, J. (1986). Enzymic hydrolysis of food proteins: Elsevier Applied Science Publishers.

Aoki, T., Decker, E. A., \& McClements, D. J. (2005). Influence of environmental stresses on stability of $\mathrm{O} / \mathrm{W}$ emulsions containing droplets stabilized by multilayered membranes produced by a layer-by-layer electrostatic deposition technique. Food Hydrocolloids, 19(2), 209-220.

Azarikia, F., \& Abbasi, S. (2016). Efficacy of whey protein-tragacanth on stabilization of oil-in-water emulsions: Comparison of mixed and layer by layer methods. Food Hydrocolloids, 59, 26-34.

Bokkhim, H., Bansal, N., Grondahl, L., \& Bhandari, B. (2015). Interactions between different forms of bovine lactoferrin and sodium alginate affect the properties of their mixtures. Food Hydrocolloids, 48, 38-46.

Chang, Y., Hu, Y., \& McClements, D. J. (2016). Competitive adsorption and displacement of anionic polysaccharides (fucoidan and gum arabic) on the surface of protein-coated lipid droplets. Food Hydrocolloids, 52, 820-826. 
Chen, X., Li, W., Zhao, Q., Selomulya, C., Zhu, X., \& Xiong, H. (2016). Physical and Oxidative Stabilities of O/W Emulsions Formed with Rice Dreg Protein Hydrolysate: Effect of Xanthan Gum Rheology. Food and Bioprocess Technology, 1-11.

Cheng, J., Ma, Y., Li, X., Yan, T., \& Cui, J. (2015). Effects of milk protein-polysaccharide interactions on the stability of ice cream mix model systems. Food Hydrocolloids, 45, 327-336.

Courts, F. L. (2013). Profiling of modified citrus pectin oligosaccharide transport across Caco-2 cell monolayers. Pharmanutrition, 1(1), 22-31.

Cuevas-Bernardino, J., Lobato-Calleros, C., Román-Guerrero, A., Alvarez-Ramirez, J., \& Vernon-Carter, E. (2016). Physicochemical characterisation of hawthorn pectins and their performing in stabilising oil-in-water emulsions. Reactive and Functional Polymers, 103, 63-71.

Dário, A. F., Hortêncio, L. M., Sierakowski, M. R., Neto, J. C. Q., \& Petri, D. F. (2011). The effect of calcium salts on the viscosity and adsorption behavior of xanthan. Carbohydrate Polymers, 84(1), 669-676.

Dickinson, E. (2008). Interfacial structure and stability of food emulsions as affected by protein-polysaccharide interactions. Soft Matter, 4(5), 932-942.

Dickinson, E. (2010). Flocculation of protein-stabilized oil-in-water emulsions. Colloids and Surfaces B-Biointerfaces, 81(1), 130-140.

Dickinson, E. (2011). Mixed biopolymers at interfaces: Competitive adsorption and multilayer structures. Food Hydrocolloids, 25(8), 1966-1983.

Dickinson, E. (2013). Stabilising emulsion-based colloidal structures with mixed food ingredients. Journal of the Science of Food and Agriculture, 93(4), 710-721.

Du, Y., Shi, S., Jiang, Y., Xiong, H., Woo, M. W., Zhao, Q., Bai, C., Zhou, Q., \& Sun, W. (2013). Physicochemical properties and emulsion stabilization of rice dreg glutelin conjugated with $\mathrm{K}$-carrageenan through Maillard reaction. Journal of the Science of Food and Agriculture, 93(1), 125-133.

Fioramonti, S. A., Martinez, M. J., Pilosof, A. M., Rubiolo, A. C., \& Santiago, L. G. (2015a). Multilayer emulsions as a strategy for linseed oil microencapsulation: effect of $\mathrm{pH}$ and alginate concentration. Food Hydrocolloids, 43, 8-17.

Fioramonti, S. A., Martinez, M. J., Pilosof, A. M. R., Rubiolo, A. C., \& Santiago, L. G. (2015b). Multilayer emulsions as a strategy for linseed oil microencapsulation: Effect of $\mathrm{pH}$ and alginate concentration. Food Hydrocolloids, 43, 8-17.

Gu, Y. S., Decker, E. A., \& McClements, D. J. (2005). Influence of pH and carrageenan type on properties of $\beta$-lactoglobulin stabilized oil-in-water emulsions. Food Hydrocolloids, 19(1), 83-91.

Gulao, E. D., de Souza, C. J. F., Andrade, C. T., \& Garcia-Rojas, E. E. (2016). Complex coacervates obtained from peptide leucine and gum arabic: Formation and characterization. Food Chemistry, 194, 680-686.

Guzey, D., \& McClements, D. J. (2006a). Formation, stability and properties of multilayer emulsions for application in the food industry. Advances in Colloid and Interface Science, 128, 227-248.

Guzey, D., \& McClements, D. J. (2006b). Influence of environmental stresses on O/W emulsions stabilized by beta-lactoglobulin-pectin and beta-lactoglobulin-pectin-chitosan membranes produced by the electrostatic layer-by-layer deposition technique. Food Biophysics, 1(1), 30-40.

Güzey, D., \& McClements, D. J. (2006). Influence of environmental stresses on O/W emulsions stabilized by $\beta$-lactoglobulin-pectin and $\beta$-lactoglobulin-pectin-chitosan membranes 
produced by the electrostatic layer-by-layer deposition technique. Food Biophysics, 1(1), 30-40.

Harnsilawat, T., Pongsawatmanit, R., \& McClements, D. J. (2006). Influence of pH and ionic strength on formation and stability of emulsions containing oil droplets coated by beta-lactoglobulin-alginate interfaces. Biomacromolecules, 7(6), 2052-2058.

Huck-Iriart, C., Rincon-Cardona, J. A., \& Herrera, M. L. (2014). Stability of Whey Protein Concentrate/Sunflower Oil Emulsions as Affected by Sucrose and Xanthan Gum. Food and Bioprocess Technology, 7(9), 2646-2656.

Joye, I. J., Nelis, V. A., \& McClements, D. J. (2015). Gliadin-based nanoparticles: Stabilization by post-production polysaccharide coating. Food Hydrocolloids, 43, 236-242.

Li, X., Li, K., Shen, Y., Niu, F., \& Fu, Y. (2016). Influence of pure gum on the physicochemical properties of whey protein isolate stabilized oil-in-water emulsions. Colloids and surfaces $A$ : Physicochemical and Engineering Aspects, 504 442-448.

Li, Y., \& McClements, D. J. (2013). Influence of non-ionic surfactant on electrostatic complexation of protein-coated oil droplets and ionic biopolymers (alginate and chitosan). Food Hydrocolloids, 33(2), 368-375.

Lim, A. S. L., \& Roos, Y. H. (2015). Stability of flocculated particles in concentrated and high hydrophilic solid layer-by-layer (LBL) emulsions formed using whey proteins and gum Arabic. Food Research International, 74, 160-167.

McClements, D. J. (2004). Protein-stabilized emulsions. Current opinion in colloid \& interface science, 9(5), 305-313.

McClements, D. J. (2010). Design of Nano-Laminated Coatings to Control Bioavailability of Lipophilic Food Components. Journal of Food Science, 75(1), R30-R42.

McClements, D. J. (2015). Food emulsions: principles, practices, and techniques: CRC press.

McClements, D. J., \& Gumus, C. E. (2016). Natural emulsifiers - Biosurfactants, phospholipids, biopolymers, and colloidal particles: Molecular and physicochemical basis of functional performance. Advances in Colloid and Interface Science, 234, 3-26.

Moreau, L., Kim, H. J., Decker, E. A., \& McClements, D. J. (2003). Production and characterization of oil-in-water emulsions containing droplets stabilized by beta-lactoglobulin-pectin membranes. Journal of Agricultural and Food Chemistry, 51(22), 6612-6617.

Niu, F., Niu, D., Zhang, H., Chang, C., Gu, L., Su, Y., \& Yang, Y. (2016). Ovalbumin/gum arabic-stabilized emulsion: Rheology, emulsion characteristics, and Raman spectroscopic study. Food Hydrocolloids, 52, 607-614.

Niu, F., Zhou, J., Niu, D., Wang, C., Liu, Y., Su, Y., \& Yang, Y. (2015). Synergistic Effects of Ovalbumin/Gum Arabic Complexes on the Stability of Emulsions Exposed to Environmental Stress. Food Hydrocolloids, 47, 14-20.

Ozturk, B., Argin, S., Ozilgen, M., \& McClements, D. J. (2015). Formation and stabilization of nanoemulsion-based vitamin $\mathrm{E}$ delivery systems using natural biopolymers: Whey protein isolate and gum arabic. Food Chemistry, 188, 256-263.

Paliandre, S., Decker, E. A., \& McClements, D. J. (2007). Improvement of stability of oil-in-water emulsions containing caseinate-coated droplets by addition of sodium alginate. Journal of Food Science, 72(9), E518-E524.

Pamies, R., Schmidt, R. R., Martínez, M. d. C. L., \& de la Torre, J. G. (2010). The influence of mono and divalent cations on dilute and non-dilute aqueous solutions of sodium alginates. 
Carbohydrate Polymers, 80(1), 248-253.

Protonotariou, S., Evageliou, V., Yanniotis, S., \& Mandala, I. (2013). The influence of different stabilizers and salt addition on the stability of model emulsions containing olive or sesame oil. Journal of Food Engineering, 117(1), 124-132.

Qiu, C., Zhao, M., \& McClements, D. J. (2015). Improving the stability of wheat protein-stabilized emulsions: Effect of pectin and xanthan gum addition. Food Hydrocolloids, 43, 377-387.

Ray, M., \& Rousseau, D. (2013). Stabilization of oil-in-water emulsions using mixtures of denatured soy whey proteins and soluble soybean polysaccharides. Food Research International, 52(1), 298-307.

Razzak, M. A., Kim, M., \& Chung, D. (2016). Elucidation of aqueous interactions between fish gelatin and sodium alginate. Carbohydrate Polymers, 148 181-188.

Rochefort, W. E., \& Middleman, S. (1987). Rheology of xanthan gum: salt, temperature, and strain effects in oscillatory and steady shear experiments. Journal of Rheology (1978-present), 31(4), 337-369.

Salminen, H., \& Weiss, J. (2014). Electrostatic adsorption and stability of whey protein-pectin complexes on emulsion interfaces. Food Hydrocolloids, 35, 410-419.

Shi, J., Xue, S. J., Wang, B., Wang, W., Ye, X., \& Quek, S. Y. (2015). Optimization of formulation and influence of environmental stresses on stability of lycopene-microemulsion. LWT-Food Science and Technology, 60(2), 999-1008.

Wang, X., Chen, Q., \& Lü, X. (2014). Pectin extracted from apple pomace and citrus peel by subcritical water. Food Hydrocolloids, 38, 129-137.

Xiang, J., Liu, F., Fan, R., \& Gao, Y. (2015). Physicochemical stability of citral emulsions stabilized by milk proteins (lactoferrin, $\alpha$-lactalbumin, $\beta$-lactoglobulin) and beet pectin. Colloids and Surfaces $A$ : Physicochemical and Engineering Aspects, 487, 104-112.

Xu, X., Liu, W., Liu, C., Luo, L., Chen, J., Luo, S., McClements, D. J., \& Wu, L. (2016a). Effect of limited enzymatic hydrolysis on structure and emulsifying properties of rice glutelin. Food Hydrocolloids, 61, 251-260.

Xu, X., Zhong, J., Chen, J., Liu, C., Luo, L., Luo, S., Wu, L., \& McClements, D. J. (2016b). Effectiveness of partially hydrolyzed rice glutelin as a food emulsifier: Comparison to whey protein. Food Chemistry, 213, 700-707.

Zhao, J., Wei, T., Wei, Z., Yuan, F., \& Gao, Y. (2015). Influence of soybean soluble polysaccharides and beet pectin on the physicochemical properties of lactoferrin-coated orange oil emulsion. Food Hydrocolloids, 44, 443-452.

Zhao, Q., Selomulya, C., Xiong, H., Chen, X. D., Ruan, X., Wang, S., Xie, J., Peng, H., Sun, W., \& Zhou, Q. (2012). Comparison of functional and structural properties of native and industrial process-modified proteins from long-grain indica rice. Journal of Cereal Science, 56(3), 


\section{Figure Captions}

Fig. 1. Effect of polysaccharide concentration on the mean particle diameter $\left(d_{3,2}\right)$ of oil-in-water emulsions ( 1 wt\% corn oil, 0.3 wt $\%$ HRG) at (a) $\mathrm{pH} 3.5$ and (b) $\mathrm{pH} 7$. (c) Photographs of emulsions containing different polysaccharide levels after $48 \mathrm{~h}$ storage at $\mathrm{pH} 3.5$ and $\mathrm{pH}$ 7. Key: XG, Xanthan gum; GA, gum arabic.

Fig. 2. Effect of polysaccharide concentration on $\zeta$-potential of oil-in-water emulsions (1 wt\% corn oil, 0.3 wt\% HRG) at (a) pH 3.5 and (b) pH 7. Key: XG, Xanthan gum; GA, gum arabic.

Fig. 3. (a) Effects of $\mathrm{pH}$ on $\zeta$-potential of emulsions ( $1 \mathrm{wt} \%$ oil droplet) in the absence and presence of different types of polysaccharide $(0.1 \mathrm{wt} \%)$; (b) Effect of $\mathrm{pH}$ on $\zeta$-potential of $0.1 \mathrm{wt} \%$ of polysaccharide solution; (c) Effects of $\mathrm{pH}$ on mean particle diameter $\left(\mathrm{d}_{3,2}\right)$ of emulsions ( $1 \mathrm{wt} \%$ oil droplet) in the absence and presence of different types of polysaccharide $(0.1 \mathrm{wt} \%)$; (d) Photographs of emulsions in the absence and presence $(0.1 \mathrm{wt} \%)$ of polysaccharides after $48 \mathrm{~h}$ storage at different $\mathrm{pH}$ values. (e) Confocal fluorescence micrographs of the influence of $\mathrm{pH}$ on selected emulsions in the absence and presence of polysaccharide (0.1 wt\%). Key: XG, Xanthan gum; GA, gum arabic.

Fig. 4. Effect of $\mathrm{NaCl}$ concentration on (a) mean particle diameter $\left(\mathrm{d}_{3,2}\right)$ and (b) $\zeta$-potential of emulsions ( $1 \mathrm{wt} \%$ oil droplet) in the absence and presence of polysaccharide $(0.1 \mathrm{wt} \%)$. (c) Impact of salt addition $(0 \mathrm{Mm}$ and $500 \mathrm{mM})$ on the confocal microscopy images of emulsions containing pectin or xanthan gum at $\mathrm{pH}$ 3.5. White scale bar indicates $20 \mu \mathrm{m}$. Key: XG, Xanthan gum; GA, gum arabic.

Fig. 5. Effect of temperature $(0 \mathrm{mM} \mathrm{NaCl})$ on the (a) mean particle diameter $\left(\mathrm{d}_{3,2}\right)$ and (b) $\zeta$-potential of emulsions ( $1 \mathrm{wt} \%$ oil droplet) containing pectin or xanthan gum $(0.1$ $\mathrm{wt} \%)$ at $\mathrm{pH} 3.5$. (c) Impact of heat treatment $\left(30{ }^{\circ} \mathrm{C}\right.$ and $\left.90{ }^{\circ} \mathrm{C}, 0 \mathrm{mM} \mathrm{NaCl}\right)$ on the confocal microscopy images of emulsions containing pectin or xanthan gum $(0.1 \mathrm{wt} \%)$ at pH 3.5. White scale bar indicates $20 \mu \mathrm{m}$. Key: XG, Xanthan gum; GA, gum arabic. 


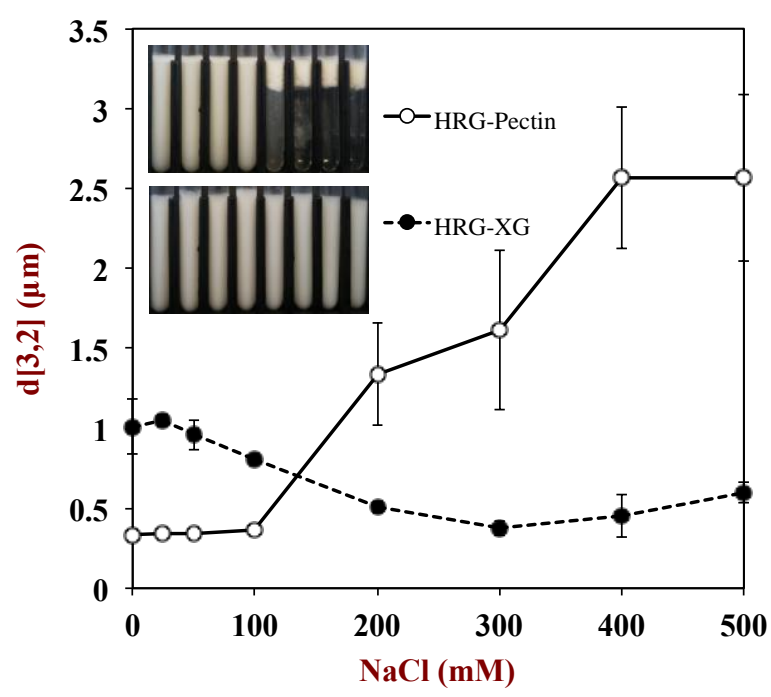


Fig.1a

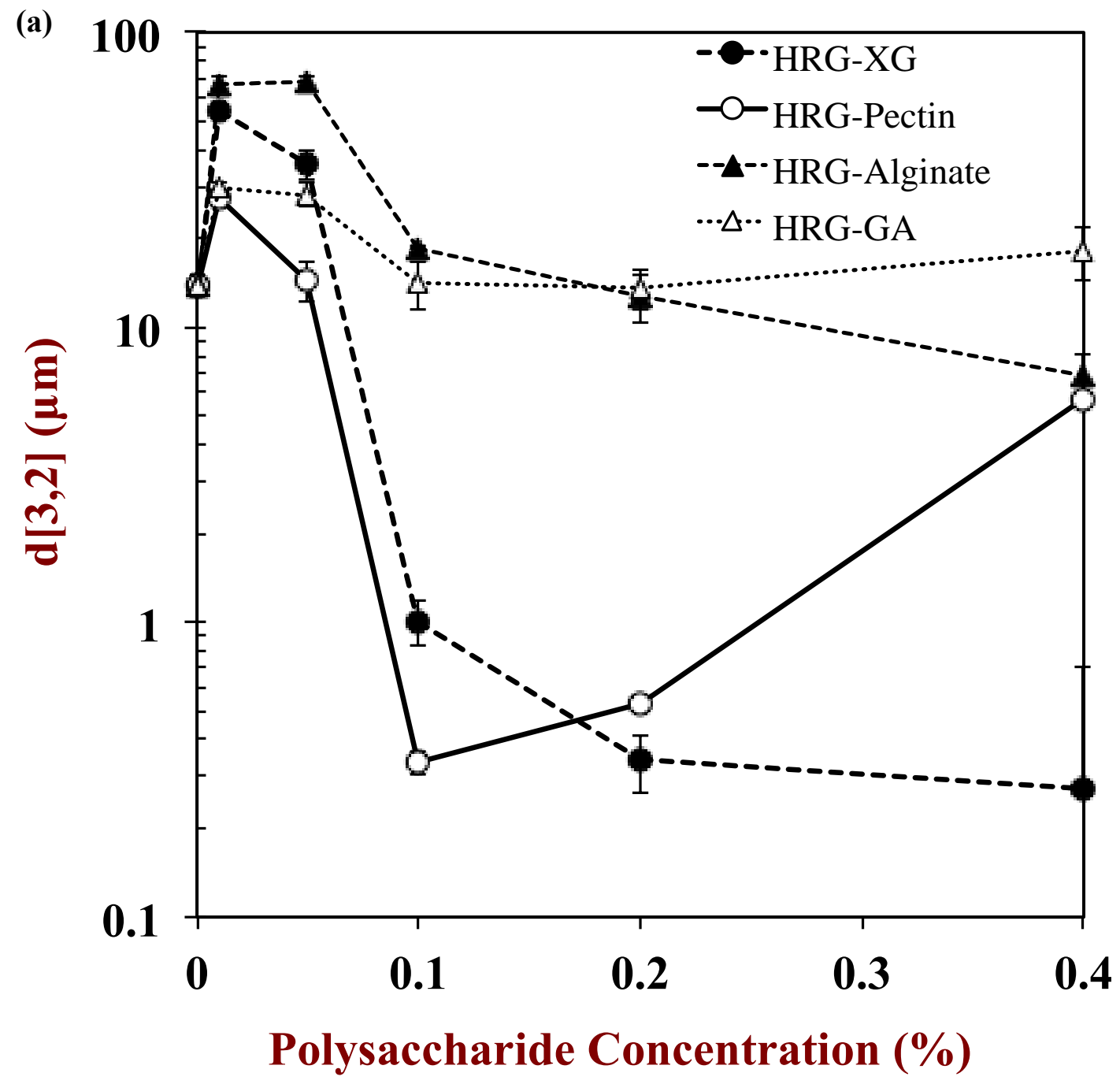


Fig.1b

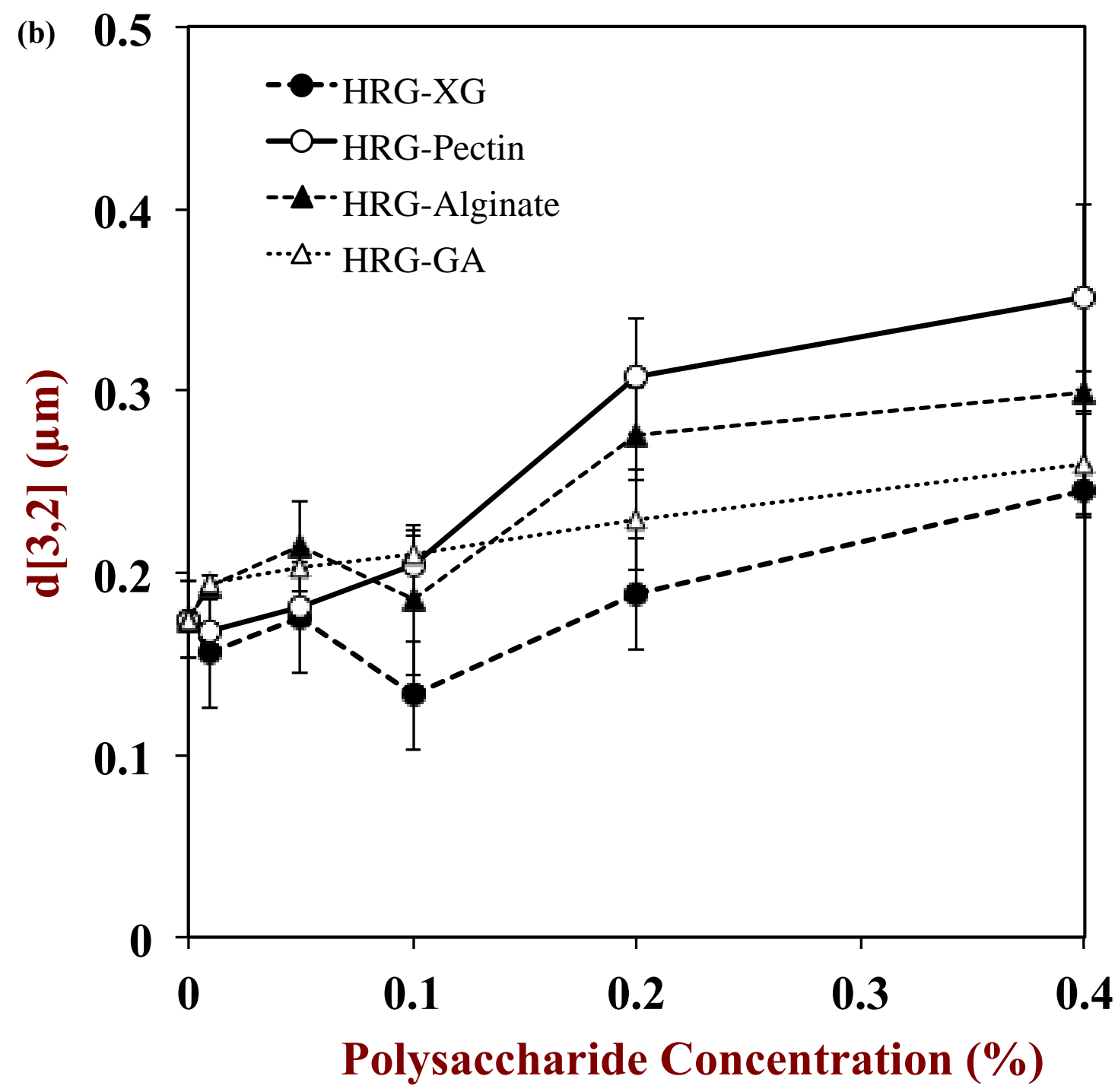


Fig.1c

(c)

pH7

pH3.5

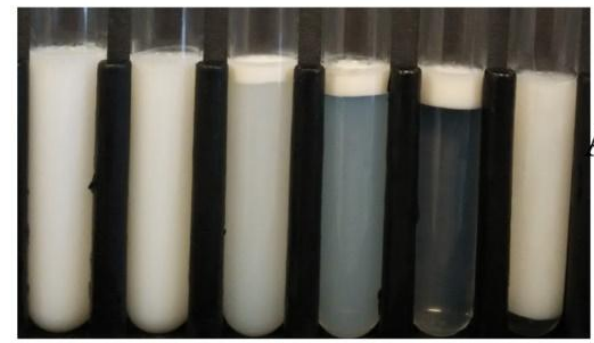

Alginate
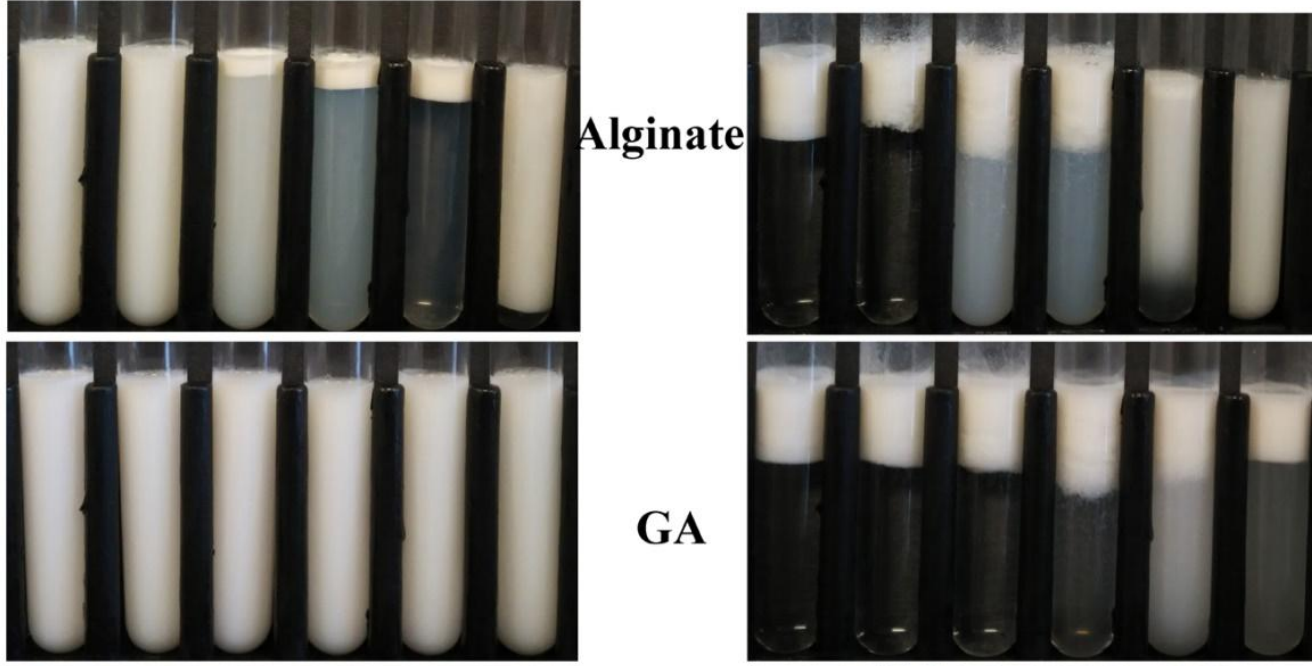

GA
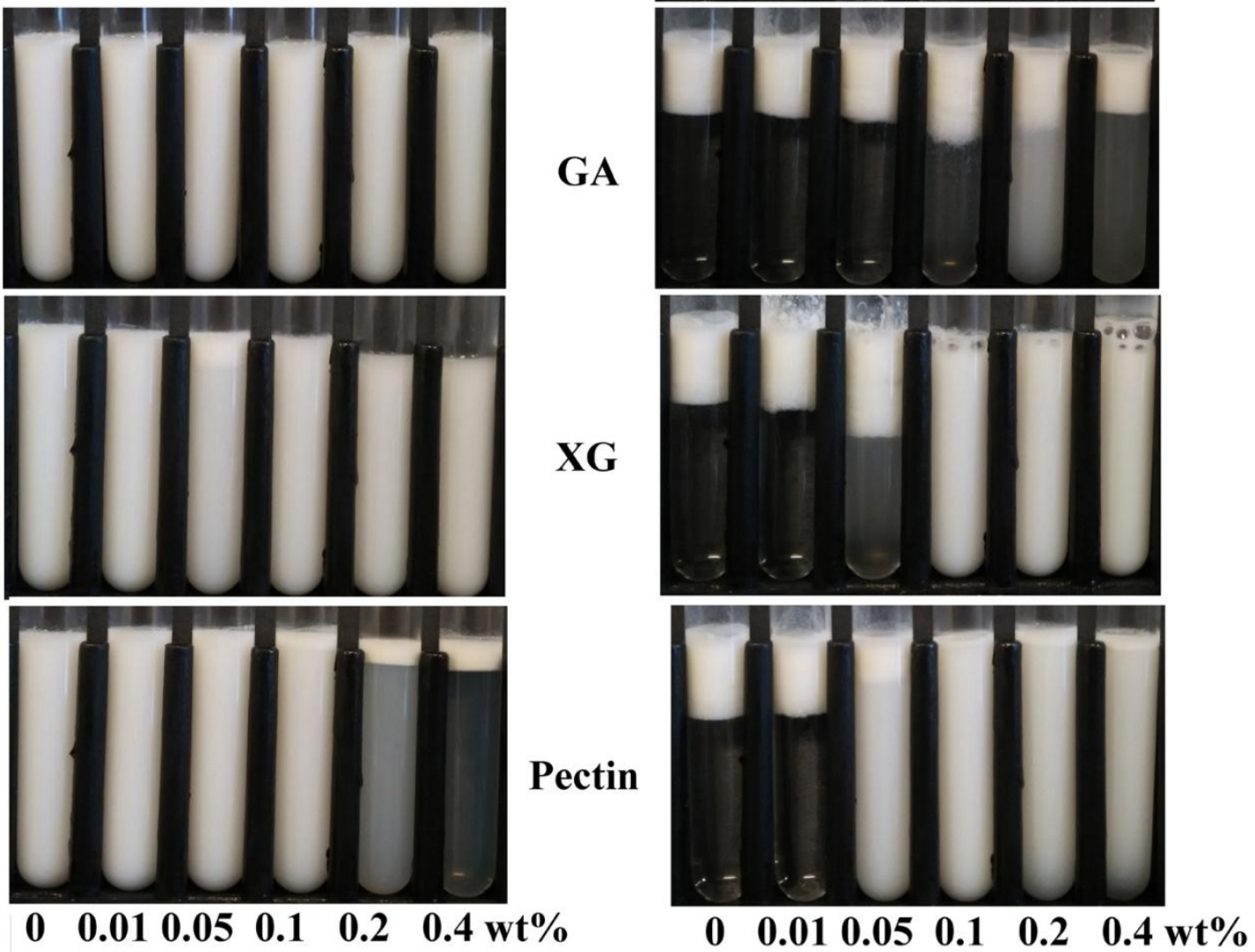

$\begin{array}{llllll}0 & 0.01 & 0.05 & 0.1 & 0.2 & 0.4 \\ \text { wt } \%\end{array}$

$\begin{array}{llllllll}0.05 & 0.1 & 0.2 & 0.4 & \text { wt } \%\end{array}$ 
Fig.2a

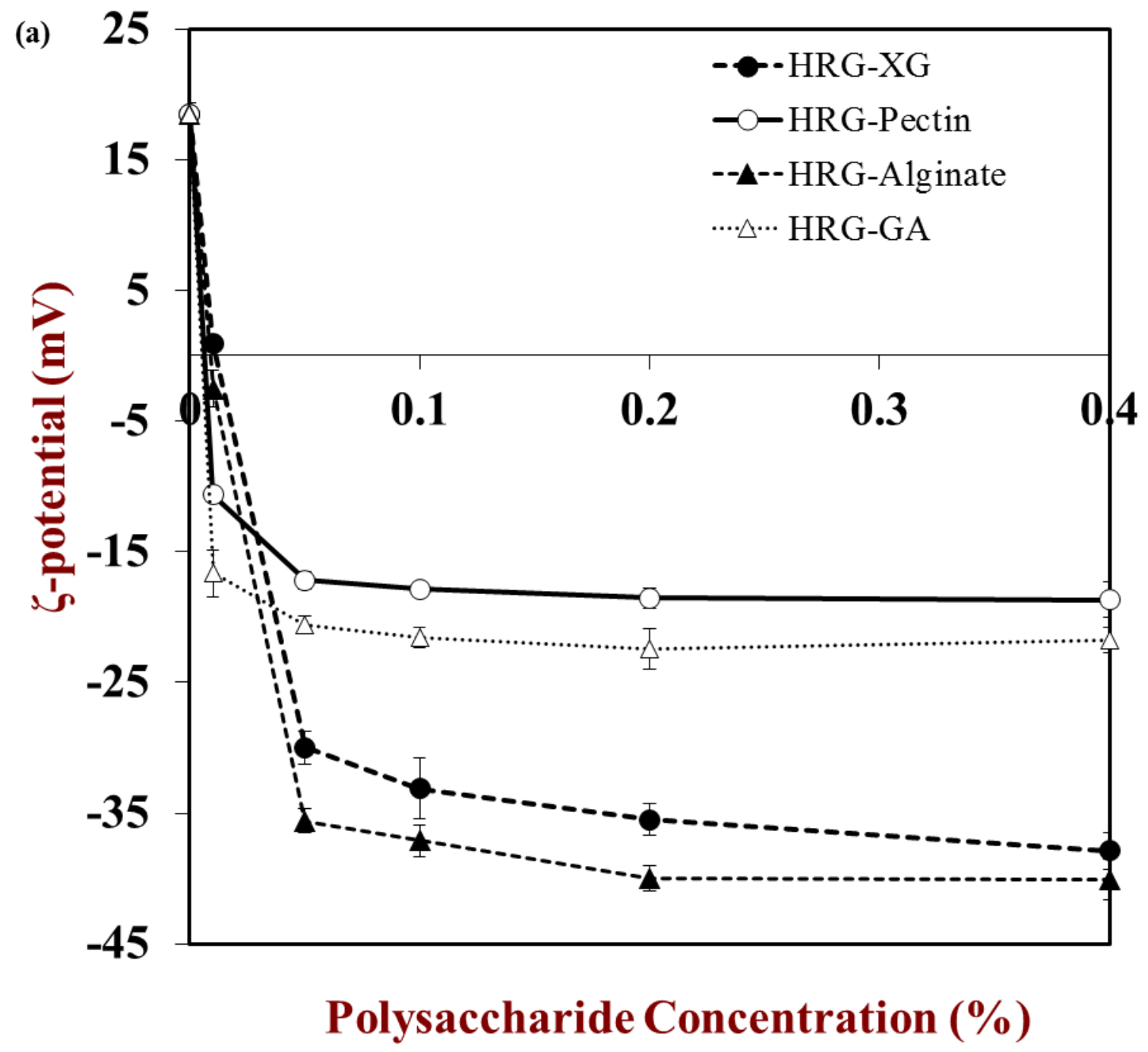


Fig.2b

(b)

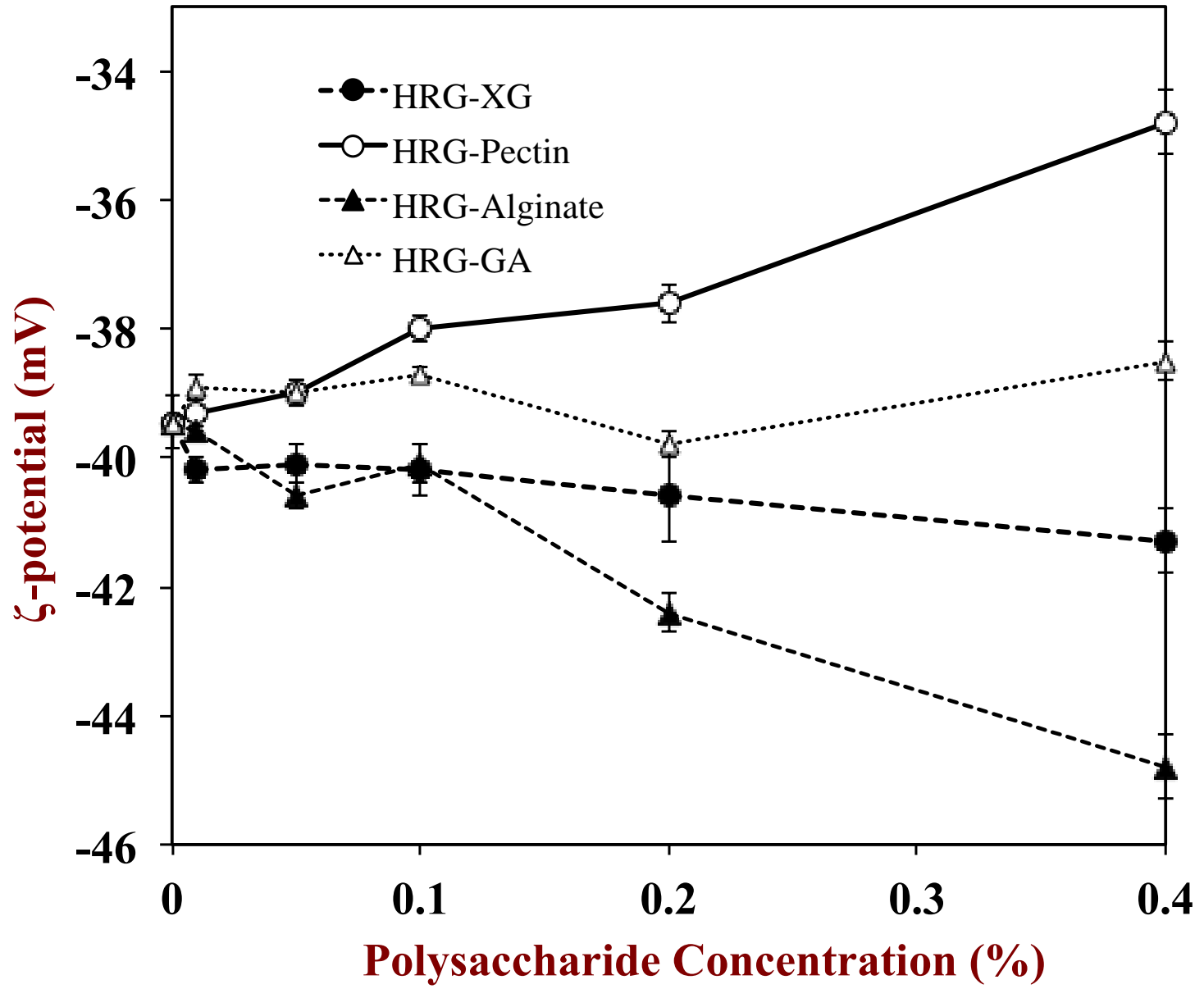


Fig.3a

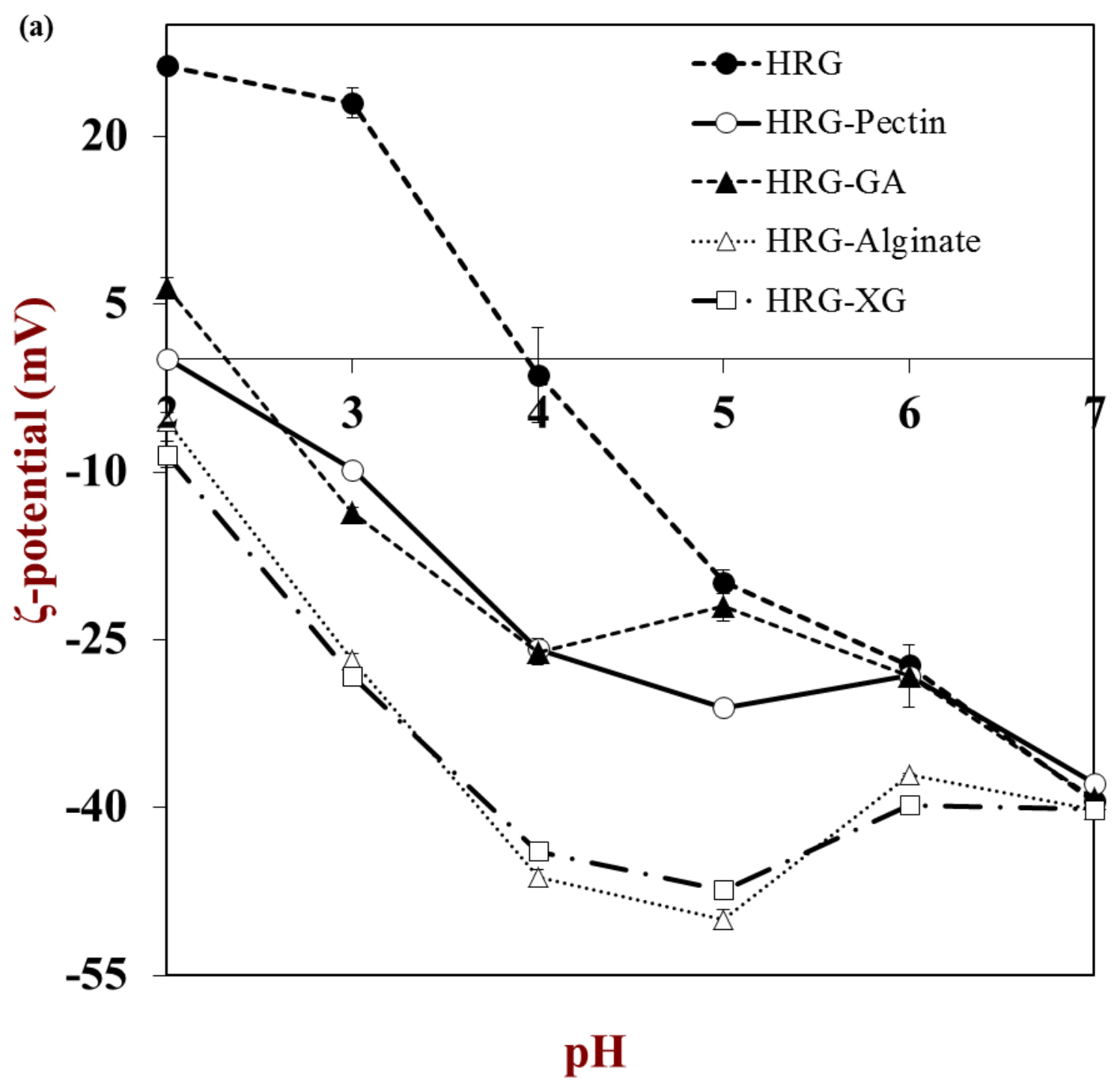


Fig.3b

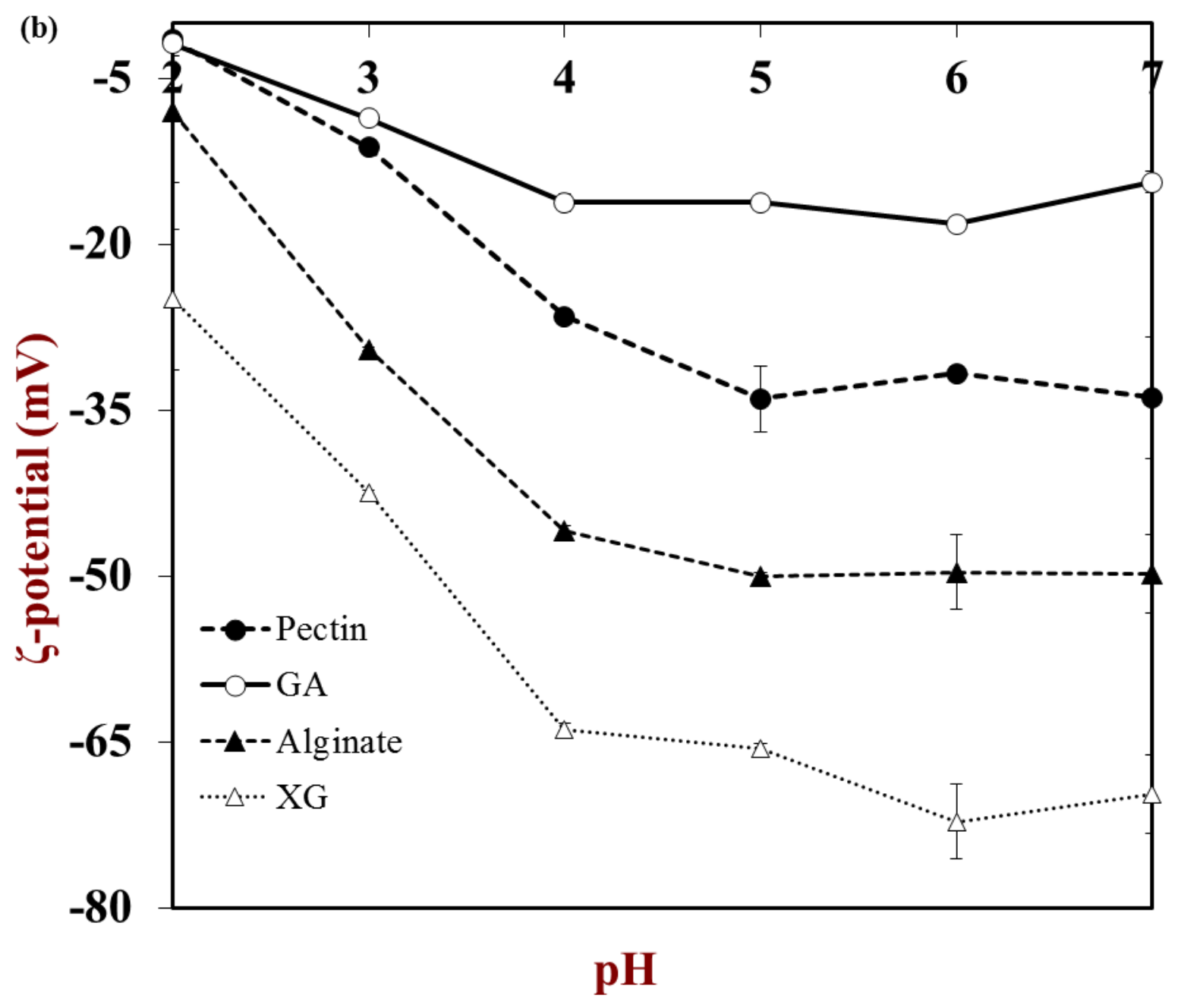


Fig.3c

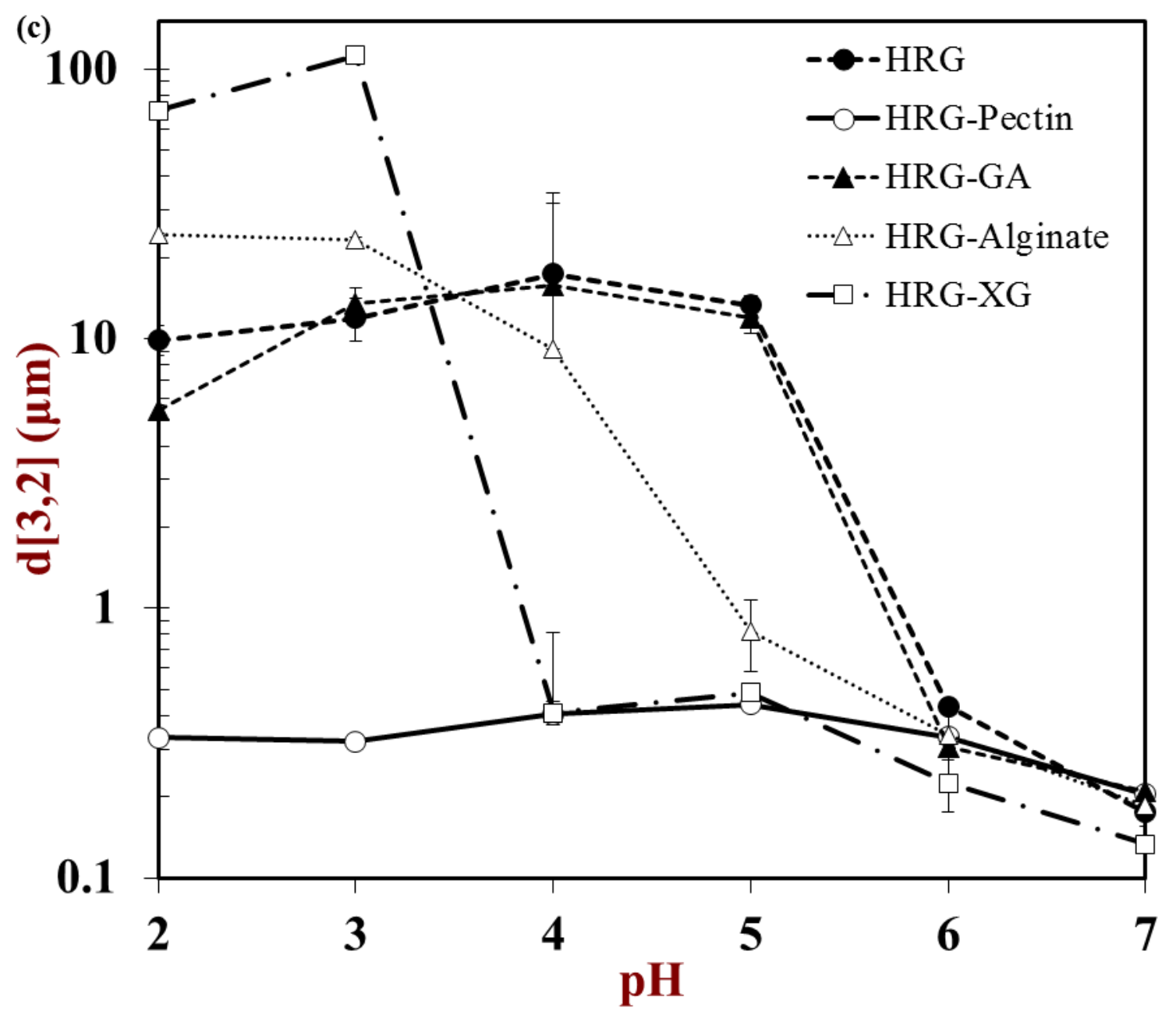


Fig.3d

(d)
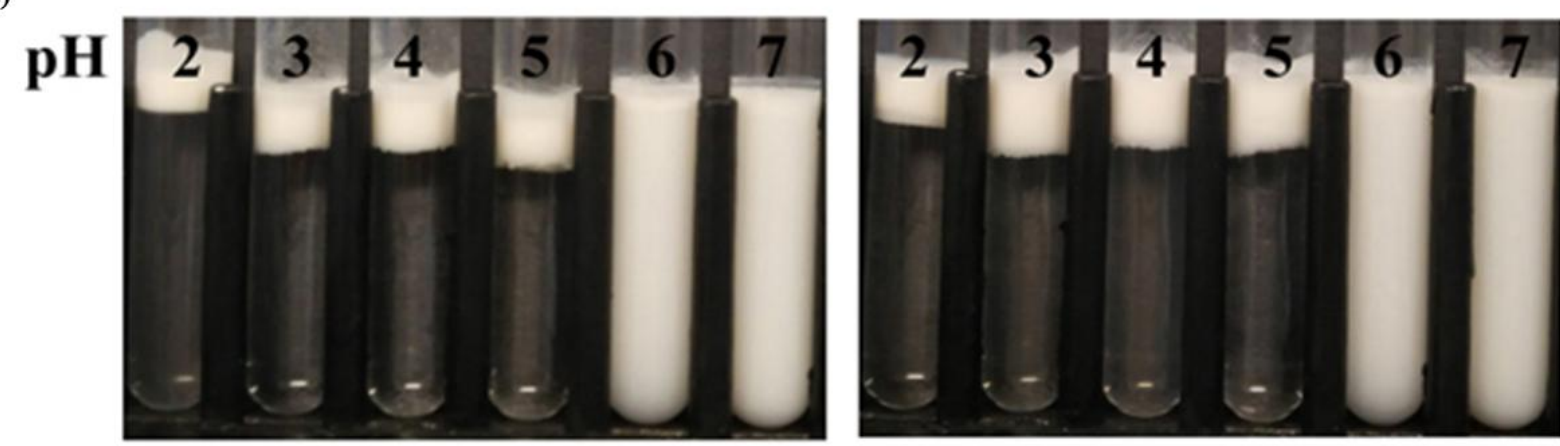

$0.3 \%$ HRG

$0.3 \% H R G+0.1 \% G A$
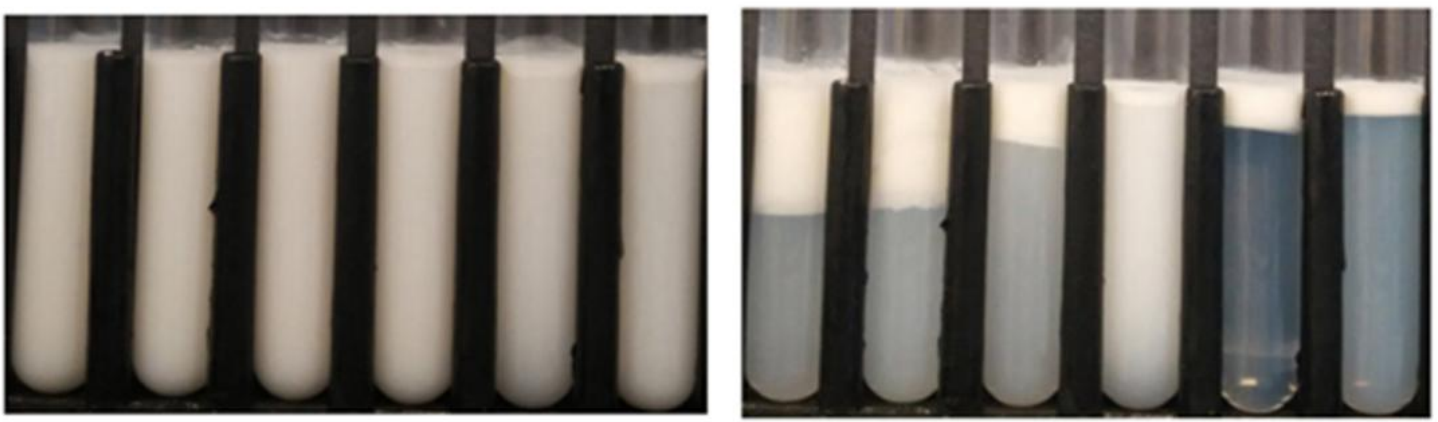

0.3\%HRG+0.1\%Pectin $\quad 0.3 \%$ HRG $+0.1 \%$ Alginate

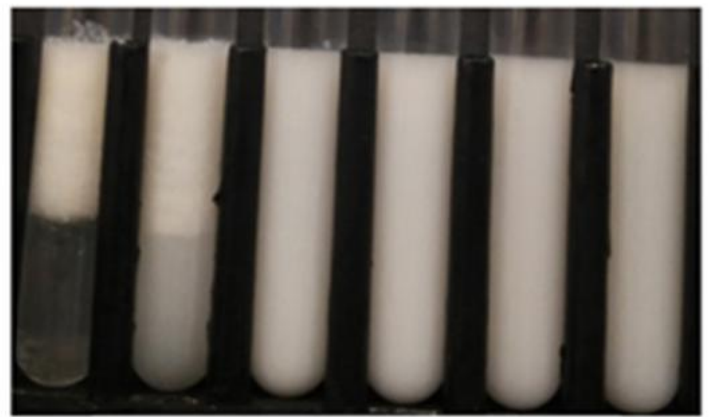

$0.3 \% H R G+0.1 \% X G$ 
Fig.3e

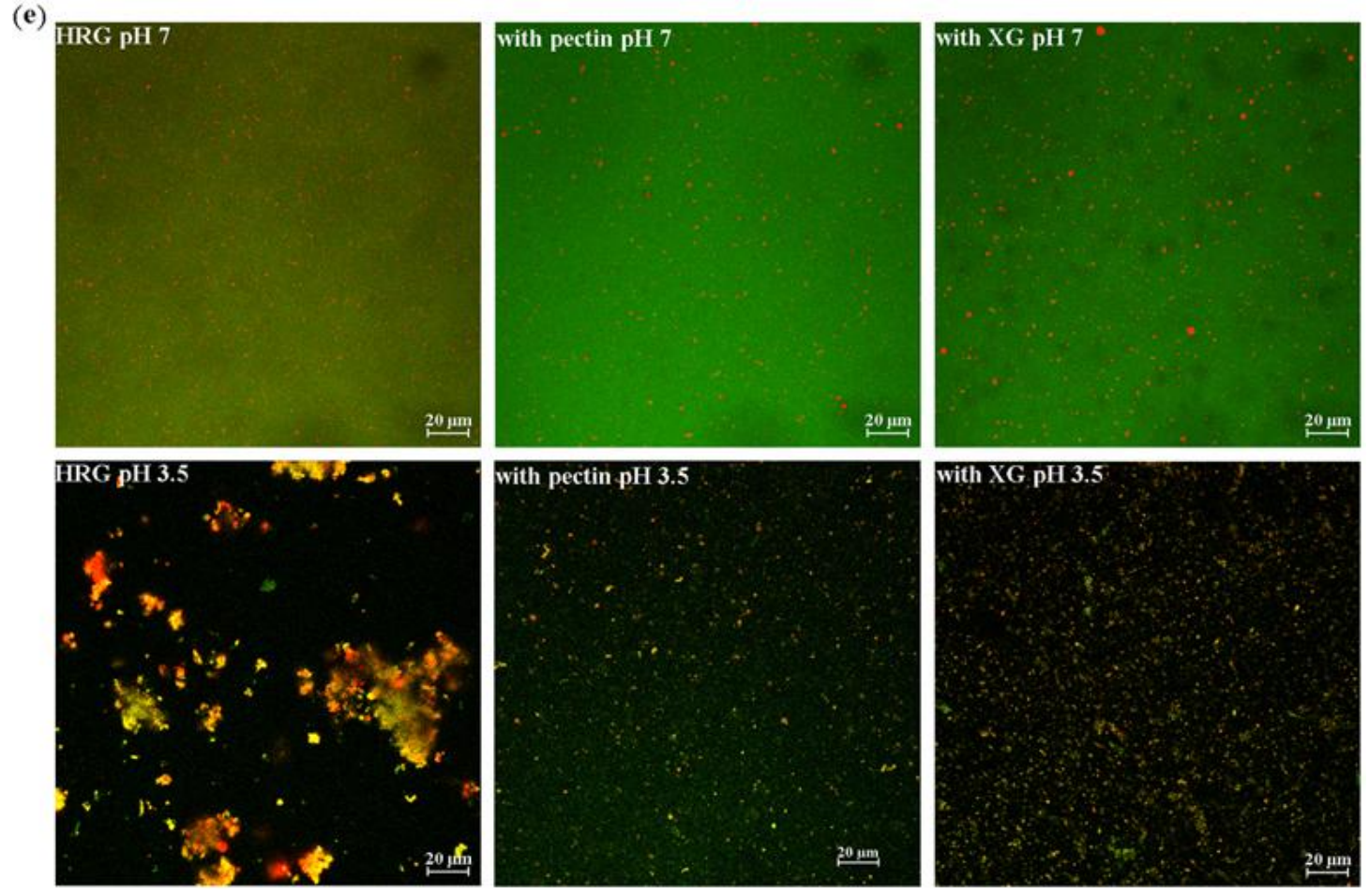


Fig.4a

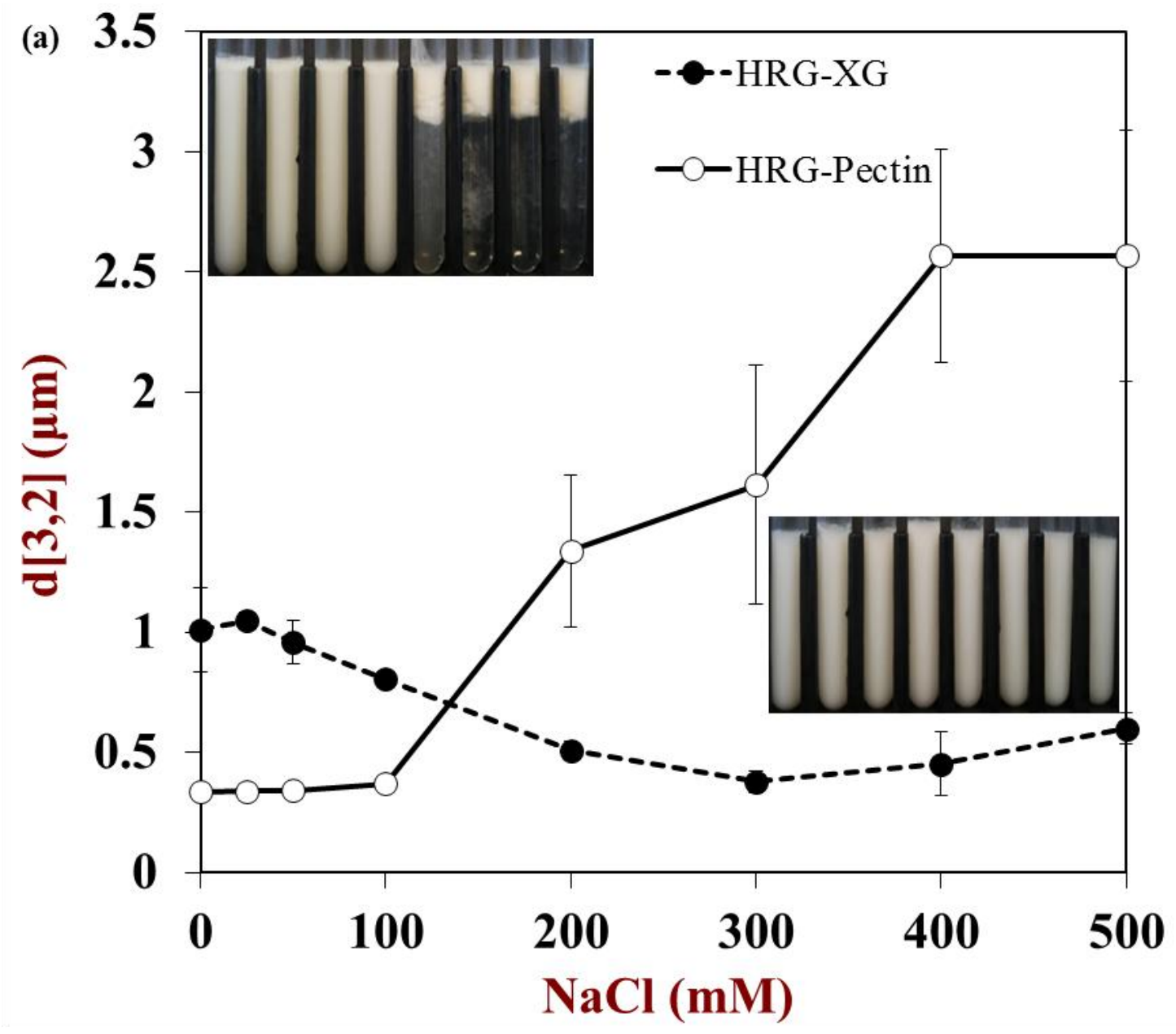


Fig.4b

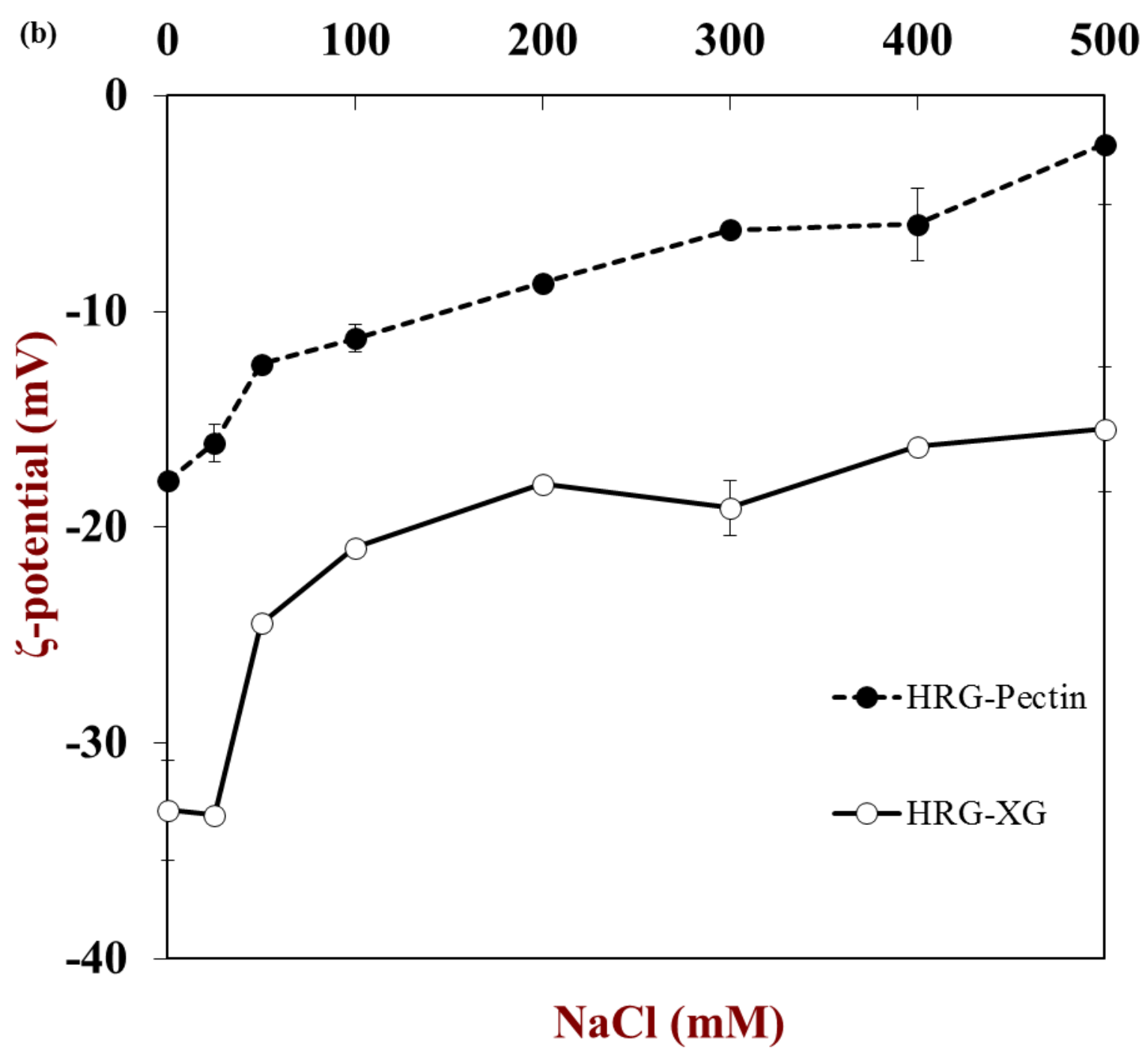


Fig.4c

(C)

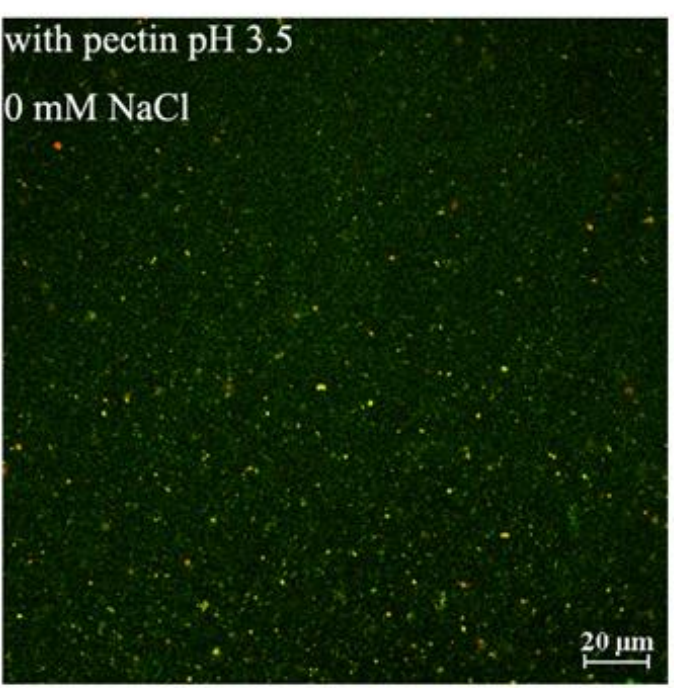

with XG pH 3.5

$0 \mathrm{mM} \mathrm{NaCl}$

with pectin $\mathrm{pH} 3.5$

$500 \mathrm{mM} \mathrm{NaCl}$

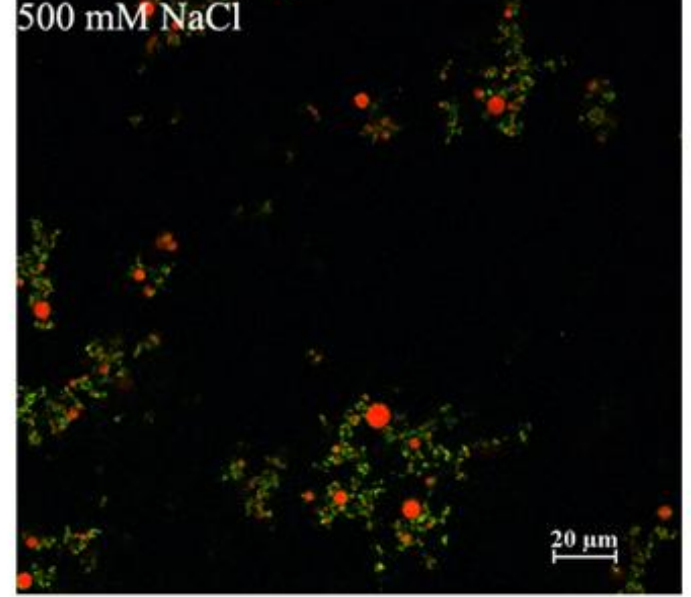

with XG pH 3.5

$500 \mathrm{mM} \mathrm{NaCl}$

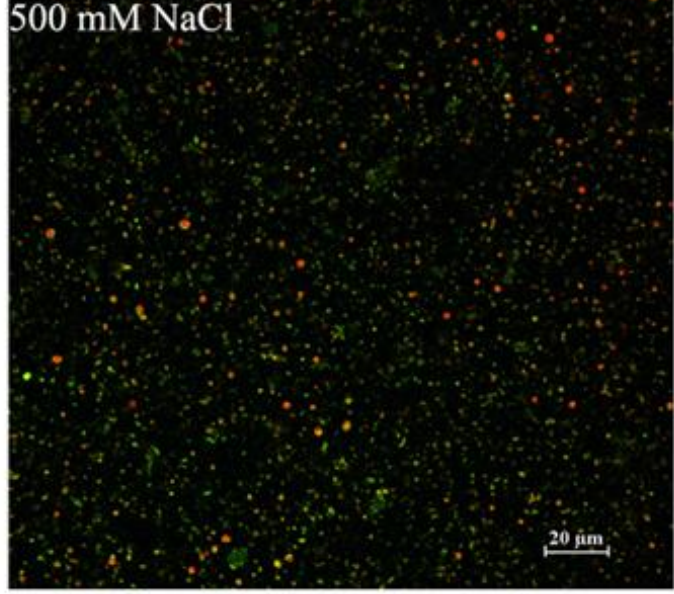


Fig.5a

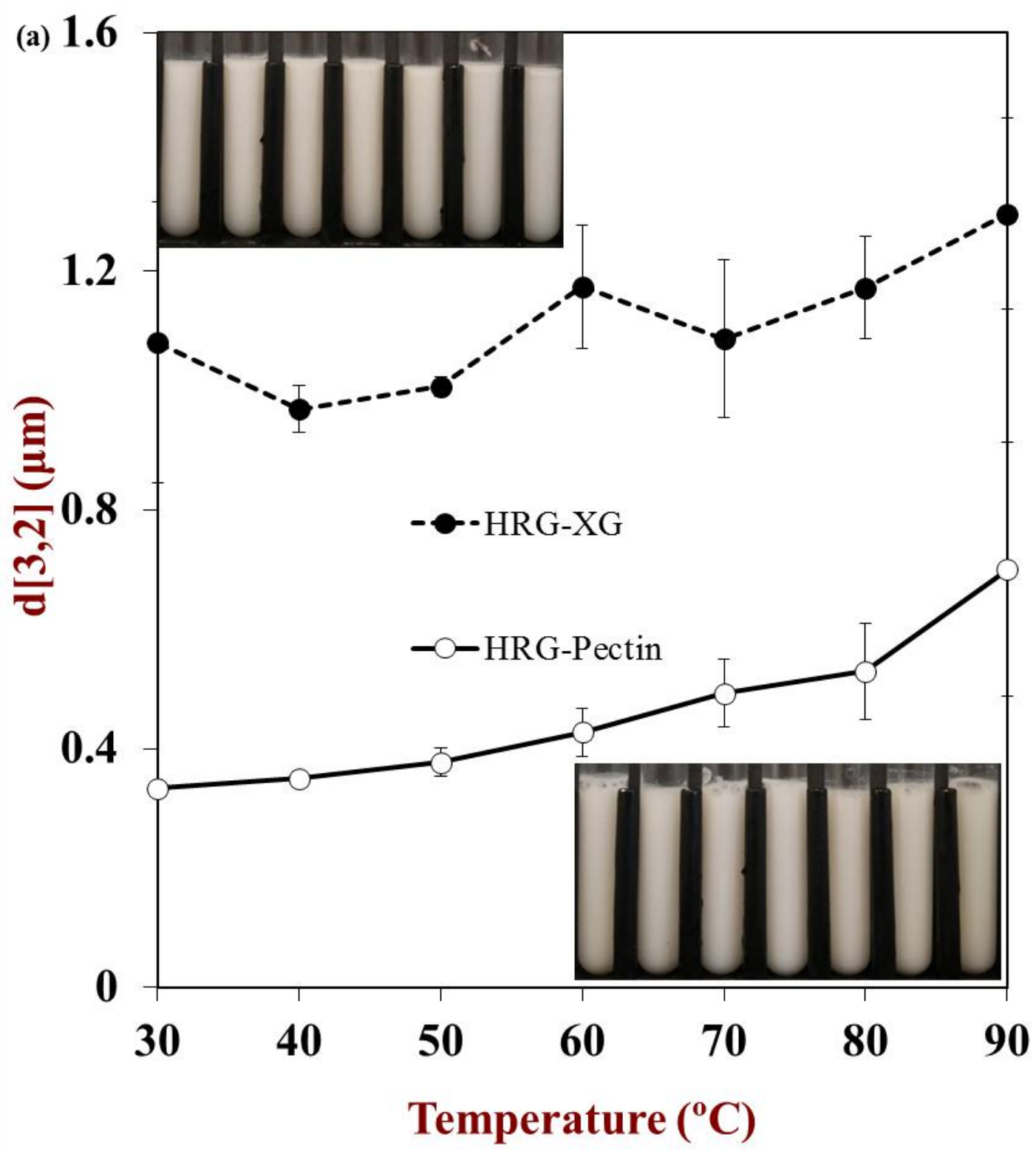


Fig.5b

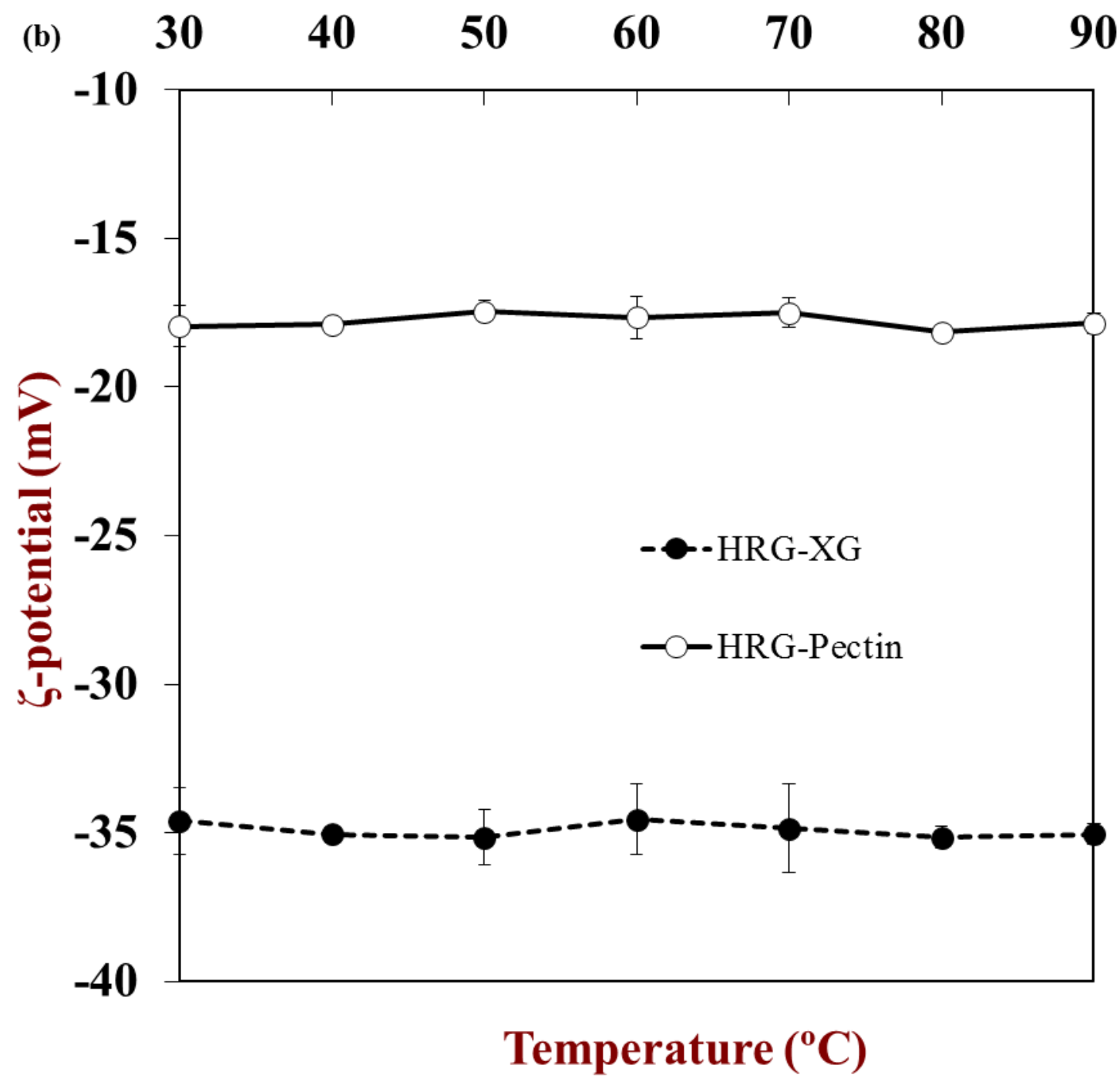


Fig.5c

(C)

with pectin $\mathrm{pH} 3.5$

$30^{\circ} \mathrm{C}$

$20 \mu \mathrm{m}$

with $\mathrm{XG}$ pH 3.5 .

$30^{\circ} \mathrm{C}$

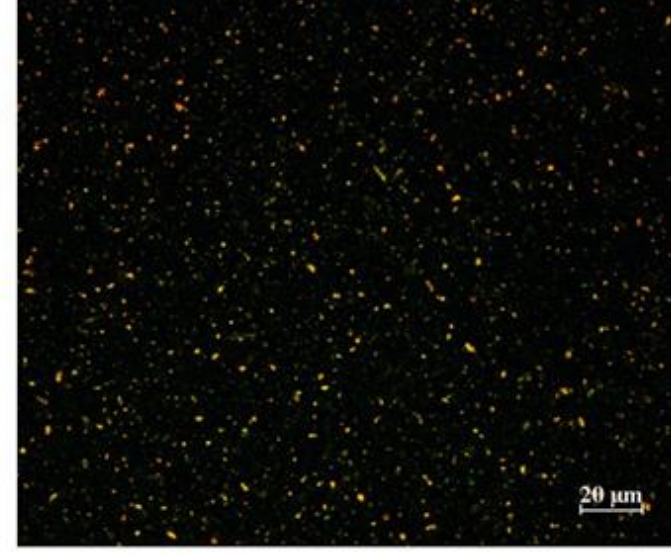

with pectin $\mathrm{pH} 3.5$

$90{ }^{\circ} \mathrm{C}$

with XG pH 3.5

$90{ }^{\circ} \mathrm{C}$

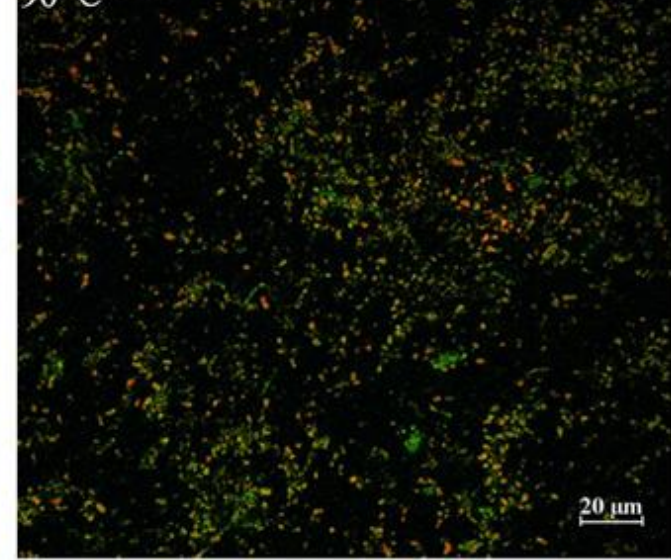

